\title{
As Transformações das Regras Internacionais sobre Violência na Ordem Mundial Contemporânea
}

\author{
Monica Herz ${ }^{1}$ \\ Roberto Vilchez Yamato ${ }^{1}$ \\ ${ }^{1}$ Pontifícia Universidade Católica do Rio de Janeiro (PUC-Rio), Rio de Janeiro, RJ, Brasil. \\ E-mail: m.herz.rio@gmail.com
}

\section{INTRODUÇÃO}

\begin{abstract}
A questão da violência é central para entender a subjetividade humana e a interação social. As sociedades modernas, em particular, têm produzido mecanismos organizacionais altamente desenvolvidos e doutrinas ideológicas que autorizam, regulam e legitimam a violência, razão pela qual a subjetividade moderna não pode ser entendida sem referência à violência organizada (Malesevic, 2010). O debate filosófico e político dos últimos 300 anos tem enfatizado a relação entre o mundo social e a violência, concentrando-se muitas vezes nas formas de limitar o seu uso. No entanto, os mesmos mecanismos ou instituições que podem regular e limitar o uso da violência também podem normalizar e naturalizar a sua presença na sociedade. Assim, as regras internacionais que têm sido concebidas e propostas para a regulação, restrição ou eliminação do uso da violência são muitas vezes as mesmas que constituem as condições de possibilidade para a autorização e legitimação de seu uso (Kennedy, 2006; Walker, 2010). De um lado, a relação entre o Estado moderno e a violência organizada tem sido largamente estudada, comumente tomando-se como ponto de referência a clássica definição weberiana que ressalta a capacidade do Estado soberano de monopolizar o uso legítimo da violência dentro de determinadas fronteiras territoriais (Weber, 1994 [1919] e 2004; Giddens, 1985). De outro lado, o estudo das relações internacionais ${ }^{1}$ tem sido marcado pela ideia de que a violência organizada é uma DADOS - Revista de Ciências Sociais, Rio de Janeiro, vol. 61, noำ 1, 2018, pp. 3 a 45.
\end{abstract}


característica do moderno sistema de Estados soberanos, sendo destes também o monopólio do uso legítimo da violência fora de seus respectivos limites territoriais (Thomson, 1994; Morgenthau, 2006; Wight, 1966; Bull, 2002; Waltz, 1979 e 2001).

Concebida a partir da imaginação político-jurídica moderna assentada em pressupostos que reinscrevem a dicotomia dentro/fora e diferenciam o espaço nacional do espaço internacional, a questão da violência tem sido a priori organizada e significada de forma dualista: se imaginada dentro das fronteiras do Estado soberano, ela é comumente aproximada do significante "crime"; se imaginada fora delas, do significante "guerra" (Wight, 1966; Walker, 1993; Galli, 2010 e 2015). A territorialização que permitiu a secularização da forma estatal característica da modernidade, subordinando a religião à forma política Westphaliana (cujus regio ejus religio) ${ }^{2}$, permitiu também a "domesticação da guerra" (Balibar, 2004:138). Nestes termos, a guerra seria concebida como "um instrumento militar público usado pelo Estado no espaço externo contra outros Estados soberanos", enquanto a polícia seria concebida como "um instrumento administrativo interno ao espaço do Estado" cujo objetivo seria assegurar "ordem e paz". Assim, a distinção entre dentro e fora associada ao Estado territorial soberano e à sua geometria política moderna articulou "uma distância lógica e política entre inimigo e criminoso, paz e guerra", distância esta que permitiu racionalizar, organizar e regular a violência na modernidade (Galli, 2010:161). Contudo, a territorialização do Estado soberano e a afirmação de sua geometria política moderna teriam sido possíveis apenas dentro da "estrutura de uma ordem global" que fora imposta sobre todo o planeta e toda a humanidade, como um "equilíbrio" cujo conteúdo pode mudar, mas "cuja forma é permanente" (Balibar, 2004:138). De acordo com essa concepção da organização e regulação inter / nacional - da violência, as regras internacionais não apenas delimitariam os espaços de crime e de guerra, mas também possibilitariam a racionalização, formalização e consequente humanização da guerra, por meio da afirmação do conceito de inimigo justo no direito internacional público e do reconhecimento da igualdade soberana dos Estados nas relações internacionais. Nesses termos, as regras internacionais sobre violência expressariam a ordem e orientação político-normativa global, o nomos da Terra (Schmitt, 2003).

Neste artigo, estudamos alguns conjuntos de regras internacionais a respeito da violência, analisando, mais especificamente, algumas 
As Transformações das Regras Internacionais sobre Violência na Ordem Mundial...

transformações que têm ocorrido desde o final do último século. Concebendo ontologicamente tais regras como regras sociais, ao mesmo tempo constitutivas e reguladoras do contínuo processo de mútua co-constituição entre agentes e estruturas na ordem mundial, processo este no qual elas próprias são reconstruídas, partimos do pressuposto de que, por meio da análise das transformações de tais conjuntos de regras internacionais sobre violência, é possível identificar mudanças significativas na arquitetura constitucional da sociedade internacional (Onuf, 1998, 2008, 2013a e 2013b; Reus-Smit, 1997, 1999, 2001, 2004 e 2013). Mais especificamente, argumentamos que tais conjuntos de regras internacionais têm passado por um contínuo e complexo processo de transformação, sobretudo desde a década de 1990, o qual expressa o deslocamento daquele tradicional dualismo doméstico/internacional, bem como reconhece o novo lugar do indivíduo nas relações internacionais. Esse processo é o objeto do estudo apresentado neste artigo. Sugerimos também que tal processo deve ser contextualizado e repensado à luz de outras mudanças e reconstruções na ordem mundial mais recente, pós-11 de setembro de 2001. Neste artigo, nos limitaremos a fazer uma breve análise da redefinição do conceito de segurança e da ressignificação do conceito de soberania, no intuito de melhor contextualizarmos aquelas transformações.

No contexto contemporâneo, após o otimismo liberal do imediato pós-Guerra Fria, o retorno da geopolítica, a nova centralidade da segurança nacional e o recrudescimento de políticas de identidade e de fronteira no discurso político internacional contemporâneo são expressões sintomáticas de uma contínua tensão entre a plasticidade incondicional que a soberania confere aos Estados no que tange ao uso da violência e os movimentos que visam limitar, condicionar e regular o uso da violência estatal. Assim, tomando como ponto de partida a impressão de que a conversa sobre violência tem se tornado mais intensa, mais generalizada e mais presente em nossas vidas, notamos, contudo, que, na medida em que nossas expectativas modernas de ordem, estabilidade e previsibilidade aumentaram, aumentou também nossa tendência a tratar a violência como um problema solucionável, o que, paradoxalmente, tem suscitado a construção de mais regras internacionais que autorizam e legitimam o seu uso. A assim chamada paz liberal, por exemplo, tem sido considerada por muitos como uma plataforma poderosa para inúmeras políticas desenvolvidas pela ONU e por diversos Estados que adotam a democracia liberal, a liberação comercial, o acesso a investimento externo e a estabilidade como funda-

DADOS - Revista de Ciências Sociais, Rio de Janeiro, vol. 61, nº 1, 2018 
ção, meio ou telos da ordem internacional. Num contexto em que o nexo entre a segurança e o desenvolvimento ganha novos contornos e significados, e o subdesenvolvimento passa a ser concebido como uma das causas das "novas guerras" num mundo neoliberal, capitalista e pós-fordista, novas práticas e políticas de resolução de conflitos são articuladas e uma nova agenda de transformação social é concebida (Duffield, 2014). Visando a paz liberal e a prevenção de conflitos, políticas e práticas de reconstrução de Estado têm promovido a democratização por meio de um processo de subjetivação e assujeitamento idealizado a partir de termos e moldes liberais. Neste mesmo contexto, no entanto, operações de paz e de reconstrução de Estados, autorizadas e legitimadas por tais nortes político-normativos, têm sido criticamente relidas e denunciadas pela violência intrínseca à sua natureza civilizatória e imperial (Paris, 1997, 2002; Richmond, 2004; Duffield, 2010, 2014; Douzinas, 2007). A análise que oferecemos aqui é complementar a esta bibliografia, embora mais especificamente preocupada com certas reconstruções político-normativas que expressam transformações fundamentais no âmbito da estrutura constitucional da sociedade internacional (Reus-Smit, 1999).

A fim de analisar certas transformações das regras internacionais sobre violência, tomamos como ponto de partida teórico a definição de Christian Reus-Smit de estrutura constitucional, entendida como uma assemblagem coerente de crenças, princípios e normas intersubjetivas que realiza duas funções principais na constituição e ordenamento da sociedade internacional: a de definir o que constitui um ator legítimo e a de definir os parâmetros básicos de ação legítima do Estado. Segundo Reus-Smit, a estrutura é constitucional porque incorpora e expressa os princípios básicos que definem e enformam as comunidades políticas internacionais; e é uma estrutura porque limita e enforma agentes e agências, direcionando-os a práticas normativas e resultados mínima e qualitativamente comuns (Reus-Smit, 1999:30-31). Composta por três elementos normativos primários, quais sejam, uma crença hegemônica sobre o propósito moral do Estado, um princípio organizacional de soberania e uma norma de justiça procedimental, a estrutura constitucional da sociedade internacional "determina a natureza de suas práticas institucionais básicas" (Reus-Smit, 1999:33). No esquema conceitual-teórico proposto por Reus-Smit, a estrutura constitucional é o nível normativo-institucional mais fundacional de um arranjo tripartite de instituições internacionais correlacionadas e ordenadas hierarquicamente. Num nível intermediário, as instituições funda- 
As Transformações das Regras Internacionais sobre Violência na Ordem Mundial...

mentais, como, por exemplo, o direito internacional, expressam as regras práticas mais básicas que estruturam e condicionam como os Estados devem coexistir e cooperar entre si. Num nível mais superficial, os regimes internacionais específicos, como, por exemplo, o do humanitarismo, o dos direitos humanos ou o da segurança coletiva, estabelecem as regras e práticas institucionais básicas em áreas temáticas particulares das relações internacionais. Assim, enquanto a estrutura constitucional condiciona a formação das instituições fundamentais, estas condicionam a formação dos regimes internacionais tematicamente específicos (ibidem:14-15). Trata-se, portanto, de uma estrutura generativa em que as estruturas institucionais mais profundas têm precedência e prioridade causais. Dito de outro modo, as instituições ou regimes internacionais mais específicos têm efeito apenas dentro de "um contexto que já é "pré-estruturado" pelos níveis mais profundos" de regras e instituições internacionais (Ruggie apud Reus-Smit, 1999:15).

Ao privilegiarmos o estudo de regras internacionais sobre violência, damos particular atenção a um elemento constitutivo comum às definições de regimes internacionais ${ }^{3}$ e instituições fundamentais ${ }^{4}$, o qual, ademais, é fundacionalmente relacionado à norma de justiça procedimental intrínseca à estrutura constitucional da sociedade internacional ${ }^{5}$. Para os fins deste artigo, adotamos a definição construtivista de regra de Nicholas G. Onuf ${ }^{6}$, de acordo com a qual a regra é um termo intermediário entre as pessoas e as sociedades, uma "declaração que diz às pessoas o que [elas devem] fazer", inter-mediando e co-constituindo $\mathrm{o}$ "processo pelo qual pessoas e sociedade[s] constituem-se uns aos outros" contínua e reciprocamente (Onuf, 1998:59). As regras aqui são concebidas como regras sociais que não apenas regulam aspectos do mundo, mas constituem a realidade social: a "textura do mundo social é, portanto, composta de regras" (Zehfuss, 2001:60). No entanto, se, de um lado, pessoas, como agentes, atuam sempre dentro de um contexto institucional, ou seja, sempre dentro de um contexto de padrões estáveis de regras e práticas relacionadas ${ }^{7}$, de outro lado, elas "atuam sobre este contexto" (Zehfuss, 2002:20). Noutras palavras, regras constituem e regulam agentes $e$ agentes constroem regras, as quais formam instituições e contextos ou arranjos sociais dentro dos quais agentes e regras são elas próprias reguladas e constituídas (Onuf, 2013a). Nesses termos, portanto, as regras internacionais analisadas neste artigo são tanto politicamente constituídas no processo de interação social quanto socialmente constituintes da ordem política mundial ${ }^{8}$.

DADOS - Revista de Ciências Sociais, Rio de Janeiro, vol. 61, nº 1, 2018 
Contudo, se as regras são padrões estáveis de relações, deve-se apontar também que tais padrões não são simétricos. Este ponto é importante porque ele nos ajuda a compreender a relação co-constitutiva entre as regras e a sociedade política (Onuf, 2013a). De acordo com Onuf, tal como Maja Zehfuss explica, a sociedade política tem duas propriedades. De um lado, há sempre regras que dão significado às atividades humanas, tornando-as socialmente inteligíveis e significativas. De outro lado, dadas as assimetrias sociais e materiais, "as regras resultam numa distribuição desigual de benefícios", o que significa dizer que elas levam a certas condições de domínio ou governo (Zehfuss, 2002:152; 2001:61). Assim, Onuf correlaciona sociedade e política por meio do "nexo regras-governo": enquanto a sociedade é baseada em regras, a "política sempre lida com relações sociais assimétricas geradas por regras, ou seja, [certas condições assimétricas de] governo" (Zehfuss, 2002:152). Nas palavras de Onuf, "onde há regras (e, portanto, instituições) há governo - uma condição onde agentes usam regras para exercer controle e obter vantagens sobre outros agentes" (1998:63). Retornando ao pensamento social alemão, mais especificamente ao paradigma do Herrschaft, traduzido por ele como o "paradigma da sociedade política", Onuf entende tal sociedade política como a expressão de "relações de superordenação e subordinação - relações mantidas por meio de regras e resultando em governo" (Onuf, 2013a:196). Relendo os três tipos de governo weberianos, Onuf sugere três condições de governo: a hegemonia ${ }^{9}$, a hierarquia ${ }^{10}$ e a heteronomia $^{11}$ (Onuf, 2013a:196-219). Para ele, as regras sociais e práticas relacionadas produzem tais condições de governo como uma condição sociopolítica da qual os agentes, como instituições, "jamais podem escapar" (Onuf, 1998:63) 12. O mundo político-social em que vivemos, portanto, é um mundo de hegemonia, hierarquia e heteronomia. E as regras são tanto constitutivas quanto constituídas por este mundo de relações assimétricas.

O nexo regras-governo sugere a relação contínua e co-constitutiva entre as regras sociais e as relações assimétricas de superordenação e subordinação, o que, noutras palavras, poderia sugerir a contínua e co-constitutiva relação entre regras e poder. No entanto, preferindo termos como "governo", "recursos" e relações "assimétricas" de "superordenação" e "subordinação", Onuf evita "usar o termo "poder"" (Onuf, 2013a:237). Não por acaso, portanto, ele pode ser criticado, como o faz Adriana Sinclair, por privilegiar um dos lados do nexo regras-governo, o das regras, deixando as discussões de governo, e con- 
As Transformações das Regras Internacionais sobre Violência na Ordem Mundial...

sequentemente de política e de poder, num segundo plano (Sinclair, 2010:15-16). Onuf, porém, parece preparado para responder a tal tipo de crítica, na medida em que resolve, pragmaticamente, adentrar o debate agente-estrutura pela via intermediária das regras, analisando, de um lado, "como as regras fazem de agentes e instituições o que eles são em relação uns aos outros" e, de outro lado, "como regras fazem de governo, e de ser governado, uma experiência social universal" (Onuf, 1998:63). Inspirado em Kant, Onuf sugeriria manter os dois modelos de prática - o "modelo de prática de regras" e o "modelo de prática de poderes" - analiticamente separados, para mostrar como cada um deles "especificam os termos da relação agente-estrutura" (Onuf, 2013b:135) ${ }^{13}$. Neste artigo, optamos, metodologicamente, por seguir esta sugestão de Onuf, optando, ademais, por dar particular atenção ao primeiro modelo de prática, uma vez que concebemos este como um estudo sobre as transformações das regras internacionais sobre a violência.

No entanto, ao fazê-lo, entendemos que o poder reside tanto na interação relacional dos agentes como no "governo sistemático que resulta das consequências de suas ações" (Guzzini, 2013:41-42). Concebendo o poder como uma produção de efeitos que se dá nas e por meio das relações sociais, moldando "as capacidades dos atores para determinar suas próprias circunstâncias e destino" (Barnett e Duvall, 2005b:3), e tomando como ponto de partida aquela concepção de relações político-sociais assimétricas, reconhecemos, com Andrew Hurrell, que as dimensões políticas da desigualdade são constitutivas da ordem política global (Hurrell, 2007). As estruturas normativas e institucionais de governança da sociedade internacional, incluindo-se aí as regras internacionais sobre violência, "refletem e reforçam os padrões mais amplos de desigualdade que marcam o sistema global", o que significa dizer que, ao contrário do que quer fazer crer a teoria liberal, as regras e instituições internacionais são expressões e "locais de poder e domínio" (Hurrell, 2007:11). Assumimos, portanto, que as transformações das regras internacionais estudadas aqui são possíveis dadas as mais diversas - e ubíquas - relações de poder na ordem mundial, incluindo-se aí aquelas que abrem espaço inclusive para discursos e práticas de resistência. Inspirados por trabalhos construtivistas de RI (Onuf, 1998, 2013a; Reus-Smit, 1999; Guzzini, 2013), reconhecemos que as regras internacionais e suas transformações são tanto produzidas e permeadas como possibilitam e reforçam relações de poder, porém, ao fazê-lo, distanciamo-nos de concepções positivistas destas relações

DADOS - Revista de Ciências Sociais, Rio de Janeiro, vol. 61, n 1, 2018 
que assumem ou pressupõem uma concepção metafísico-causal de poder. Dito isto, na próxima seção, brevemente apresentamos os cinco regimes ou conjuntos de regras internacionais sobre violência estudados aqui. Na seção subsequente, analisamos as transformações de tais conjuntos de regras internacionais nos contextos do pós-Guerra Fria e do pós-11 de setembro de 2001. Daí, então, partimos para a conclusão deste trabalho.

\section{AS REGRAS INTERNACIONAIS SOBRE VIOLÊNCIA}

\section{Direito Internacional Humanitário}

O direito internacional humanitário tem sua origem associada às distinções afirmadas desde o século XIX entre a paz e a guerra, a guerra e o crime, as esferas públicas e privadas, os atores civis e combatentes, e as ações militares e policiais. Essas distinções têm o objetivo de limitar o uso da violência pelo Estado soberano em tempos de guerra, ao mesmo tempo racionalizando o conflito armado internacional e minimizando o desnecessário sofrimento humano (Sassòli e Bouvier, 1999). Historicamente, a criação do Comitê Internacional da Cruz Vermelha (CICV) e a confecção da Convenção de Genebra de 1864 sobre o tratamento de doentes e feridos são marcos fundacionais da construção moderna deste regime. Normativamente, ele é identificado como um conjunto de regras internacionais composto tanto pelo chamado Direito de Haia, cujo foco é a condução da guerra, como pelo Direito de Genebra, cujo foco é lançado sobre as condições das vítimas de guerra nas mãos inimigas (Kalshoven e Zegveld, 2001). Inicialmente, tal regime concentrava-se exclusivamente nas guerras entre os Estados soberanos, mas, a partir de 1949, conflitos armados de caráter "não internacional" também passaram a ser reconhecidos e regulados no âmbito deste regime, tal como estabelecido no artigo 3ํㅜ comum das Convenções de Genebra de 1949. Nesse contexto, a ONU tem sido um importante fórum para o desenvolvimento deste conjunto de regras, particularmente desde a aprovação da resolução 2444 que convidou o Secretário-Geral, em consulta ao CICV, a realizar estudos sobre o respeito aos direitos humanos em conflitos armados.

Os princípios humanitários, de necessidade militar, de distinção e de proporcionalidade seriam afirmados como os pilares normativos deste regime, fundamentando a criação de regras internacionais de intervenção militar e de ação humanitária. À luz de tais princípios, o enfra- 
As Transformações das Regras Internacionais sobre Violência na Ordem Mundial...

quecimento das forças militares inimigas, o único objetivo legítimo durante a guerra, e a necessidade militar devem ser equilibrados em relação aos custos humanos e aos princípios humanitários (Sassòli e Bouvier, 1999). Assim, se, de um lado, os ataques devem ser direcionados a alvos militares identificados e os combatentes podem ser atacados diretamente, de outro lado, civis podem ser mortos apenas como um efeito "colateral" do uso da violência (Rogers, 2004). Evitar danos acidentais e a morte de civis são considerados propósitos fundamentais deste regime, razão pela qual, preferencialmente, avisos devem ser dados quando um ataque pode gerar danos e perdas civis (Blix, 1978). De modo geral, o regime prescreve certa imunidade à violência nos conflitos armados domésticos e internacionais, privilegiando a proteção de alguns grupos, como, por exemplo, a população civil inimiga, os combatentes feridos e os prisioneiros de guerra. Não por acaso, o debate sobre quais são os alvos i/legítimos em situação de guerra ser uma das consequências jurídicas mais relevantes desse conjunto de regras internacionais.

\section{Humanitarismo}

O humanitarismo tem como base o princípio ético de cuidado com pessoas desconhecidas que vivem em lugares distantes, sendo a criação do CICV tradicionalmente reconhecida como o seu momento de fundação institucional (Douzinas, 2007). De acordo com Michael Barnett, três marcas distintivas poderiam ser destacadas quando do surgimento do humanitarismo como uma cultura no início do século XIX: "a assistência para além das fronteiras, a crença de que a ação transnacional estava relacionada de alguma forma ao transcendente e a crescente organização e governança das atividades criadas para proteger e melhorar a humanidade" (Barnett, 2011:10). De modo geral, as regras do humanitarismo estabelecem acesso a espaços de violência e sofrimento em massa, prescrevendo uma abordagem universalista pautada no seu caráter, supostamente, não político e na sua "neutralidade diante dos protagonistas de guerras e desastres naturais" (Douzinas, 2007:58). O humanitarismo tem como fundação normativa os princípios de imparcialidade $^{14}{ }^{\text {, neutralidade }}{ }^{15}$ e independência ${ }^{16}$.

As práticas humanitárias estão profundamente enraizadas nos conceitos iluministas de progresso e humanidade e nos movimentos sociais de reforma que marcaram o século XIX e buscaram a abolição da escravidão e a melhoria de condições para a classe trabalhadora e as mulhe-

DADOS - Revista de Ciências Sociais, Rio de Janeiro, vol. 61, nº 1, 2018 
res. Barnett identifica três eras de humanitarismo. A primeira, imperial, que teria tomado lugar entre o início do século XIX e a Segunda Guerra Mundial, teria sido marcada pelas ideias religiosas e liberais, assim como teria representado parte da perspectiva civilizatória da elite europeia. A segunda, a do neo-humanitarismo, que teria tomado lugar no pós-Segunda Guerra até o final da Guerra Fria, teria sido marcada pelo aumento do número de Estados e pelo humanitarismo intergovernamental. A terceira, a atual era "liberal", poderia ser caracterizada pelo envolvimento humanitário na reconstrução pós-conflito e na construção da paz, bem como por sua preocupação com as causas do sofrimento humano (Barnett, 2011:29). O humanitarismo tornou-se um importante regime internacional; alguns diriam, ideologia (Walzer, 2011). Suas regras são o resultado da transformação dos conceitos de humano e humanidade (Douzinas, 2007), entendidos aqui em termos universais, não relativistas. Assim, este conjunto de regras coloca em questão o tradicional dualismo doméstico/internacional, particularmente quando repensado em relação ao lugar próprio do indivíduo na ordem mundial.

\section{Direito Internacional dos Direitos Humanos}

Famosamente, a Declaração dos Direitos do Homem e do Cidadão reconheceu que "a preservação dos direitos naturais do homem era o objetivo de toda associação política" (Freeman, 2002:24), conjugando-se "os Direitos do Homem com a soberania nacional" (Arendt, 2011:305). Mas, se, com esta nova concepção de Estado-Nação, a afirmação dos direitos humanos, de um lado, ganhou concretude nacionalmente, de outro lado, ela perdeu em universalidade, uma vez que tais direitos teriam valor "somente no âmbito do Estado" que os reconhecesse (Bobbio, 1992:30). Ademais, tal como Hannah Arendt sugeriu num influente capítulo de seu Origens do Totalitarismo, haveria uma relação fundamental entre o declínio do Estado-Nação e o fim dos direitos do homem, na medida em que ter "um direito de ter direitos" implicaria um direito de pertencer a algum tipo de comunidade organizada: "[s]ó com uma humanidade completamente organizada [por meio de Estados-Nações], a perda do lar e da condição política de um homem pode equivaler à sua expulsão da humanidade" (Arendt, 1989:330). À sombra da arquitetura da sociedade internacional interestatal, os Estados-Nação pactuam uma espécie de "conspiração de silêncio" sobre os "direitos e deveres de seus respectivos cidadãos" (Bull, 2002:79-80). 
As Transformações das Regras Internacionais sobre Violência na Ordem Mundial...

O massacre de seus próprios cidadãos pelo Estado não era tipificado como um crime internacional: se, de um lado, o governo nazista alemão poderia ser internacionalmente responsabilizado pelo tratamento desumano de cidadãos de outras nacionalidades nos territórios por ele ocupados, de outro lado, o assassinato por ele de seus próprios nacionais poderia significar o mero exercício de "seus direitos soberanos" (Donnelly, 2007:4). Não por acaso, portanto, o Holocausto ter sido considerado o evento catalisador que fez com que os direitos humanos fossem reconhecidos como uma questão própria da política mundial, tendo os horrores do nazismo suscitado a reconstrução internacional dos "direitos do homem" como "direitos humanos" (Freeman, 2002:31). Os direitos humanos só passaram a ser reconhecidos, internacionalmente, a partir do final da Segunda Guerra Mundial, com o estabelecimento do Tribunal de Nuremberg e a constituição da ONU (Alston e Goodman, 2013). De um lado, o Tribunal de Nuremberg foi paradigmático porque tipificou "crimes contra humanidade" e responsabilizou criminal e internacionalmente representantes do governo nazista alemão por "ofensas cometidas contra indivíduos cidadãos, não estados, e indivíduos que, em muitos dos casos, eram nacionais, e, não, estrangeiros" (Donnelly, 2007:5). De outro lado, a criação da ONU foi fundamental, na medida em que sua Carta constitutiva estabeleceu as bases normativas e institucionais deste novo regime, cujo marco normativo paradigmático é a Declaração Universal dos Direitos Humanos de 1948 (Alston e Goodman, 2013).

\section{Direito Internacional Penal}

O direito internacional penal "é um conjunto de regras internacionais concebidas tanto para proscrever crimes internacionais como para impor aos Estados a obrigação de processar e punir pelo menos alguns daqueles crimes" (Cassese, 2003b:721). Tais regras internacionais ensejam a responsabilização penal dos indivíduos perpetradores dos mais sérios crimes internacionais: "genocídio, crimes contra a humanidade e crimes de guerra" (Schabas e Bernaz, 2013:1). De acordo com Antonio Cassese, a definição de crime internacional envolve, cumulativamente, quatro elementos principais: (i) violações a regras internacionais gerais; (ii) regras que buscam proteger valores comunitários internacionais fundamentais; (iii) interesse universal de reprimir tais crimes, expresso e operacionalizado pelo princípio de jurisdição universal; e (iv) impossibilidade do suposto criminoso, mesmo sendo este um representante oficial de Estado, reivindicar imunidade à jurisdição

DADOS - Revista de Ciências Sociais, Rio de Janeiro, vol. 61, nº 1, 2018 
internacional ou estrangeira (Cassese, 2003a:23-24). De modo geral, trata-se de um regime internacional que busca responder às "sérias violações dos padrões internacionais de direitos humanos e de direito humanitário" (Cassese, 2003a:3). Não por acaso, este regime envolve a relação fundamental entre o direito internacional penal, o regime de direitos humanos e o regime de direito humanitário (Ratner e Abrams, 2001; Simpson, 2007).

Nesse sentido, Sir Hersh Lauterpacht destacou que a tipificação de crimes contra a humanidade em Nuremberg também havia significado a afirmação internacional dos direitos humanos, na medida em que se reconhecia a existência de direitos fundamentais baseados numa ordem normativa superior à do Estado soberano (Lauterpacht, 1968); noutros termos, "metanacional" (Cassese 2003a:70). Historicamente, o direito internacional penal tem sua origem associada à tipificação do crime internacional de pirataria, sendo o pirata comumente identificado como "inimigo da humanidade" (Simpson, 2007; Heller-Roazen, 2009; Policante, 2015). Posteriormente, tipificaram-se os crimes de escravidão e os crimes de guerra. Contudo, apesar de tais construções normativas, o primeiro grande esforço de construção do direito internacional penal deu-se apenas no final da Segunda Guerra Mundial, com o estabelecimento dos Tribunais Militares Internacionais de Nuremberg e Tóquio (Schabas e Bernaz, 2013). Mas, com o início da Guerra Fria, o direito internacional penal viu seu primeiro grande esforço de construção normativa e institucional perder fôlego e força rapidamente. Como Schabas e Bernaz destacam, o direito internacional penal passaria por seu grande renascimento apenas na década de 1990 (Schabas e Bernaz, 2013).

\section{Segurança Coletiva}

O conceito de segurança internacional ${ }^{17}$ envolveu, durante a maior parte do século XX, diferentes debates, negociações e construções de instituições voltadas para a manutenção da ordem internacional, entendida em termos da administração dos conflitos entre Estados e da regulação do uso internacional da violência. Após o final da Primeira Guerra Mundial, o Pacto da Liga das Nações havia estabelecido um sistema de segurança coletiva que convocava os Estados-membros a reagir coletivamente a qualquer forma de agressão. Um "ato de guerra" contra um membro da organização seria considerado um ato de guerra contra todos (Liga das Nações, 1924). Acreditava-se que uma 
As Transformações das Regras Internacionais sobre Violência na Ordem Mundial...

poderosa forma de dissuasão tinha sido criada como uma reação automática, a ser institucionalizada, reunindo o poder de todos os Estados contra agressores hipotéticos (Claude, 1984). Diante do fracasso deste sistema na década de 1930, e dos horrores da Segunda Guerra Mundial, a nova organização internacional concebida para manter a ordem e a estabilidade mundiais geraria, então, um novo sistema de segurança coletiva. Mais universal, e mais adequado às relações de poder entre os Estados, este novo sistema efetivamente trataria a soberania e o poder das grandes potências em termos distintos dos demais membros da ONU, tal como expresso no poder de veto dos cinco membros permanentes de seu Conselho de Segurança.

Em contraste àqueles termos da Liga das Nações, a ONU seria constituída em 1945 com o propósito de "manter ou restabelecer a paz e a segurança internacionais" (ONU, 1945). Neste novo regime de segurança coletiva, claras limitações foram impostas ao uso da violência pelos Estados. Enquanto a autodefesa continuou sendo considerada legal no âmbito da nova ordem normativa, outras formas do uso da violência passaram a ser consideradas legais apenas quando autorizadas pelo Conselho de Segurança, de acordo com o estabelecido no Capítulo VII da Carta da ONU. No entanto, mesmo nos casos de autodefesa, determinou-se que o Conselho de Segurança deve ser informado, podendo ele tomar qualquer ação que considere necessária (Gray, 2008:87). De modo geral, os proponentes do sistema de segurança coletiva frisavam que este poderia gerar mais cooperação, menos violência, bem como mitigar o dilema da segurança (Claude, 1962). Contudo, o sistema de segurança coletiva não funcionou como o esperado durante a Guerra Fria. Em parte, devido ao uso do veto pelos cinco membros permanentes; em parte, pela diferente natureza das guerras que ocorreram durante o período. Nessas circunstâncias, a geração dos mandatos para as operações de paz tornou-se uma grande contribuição do Conselho de Segurança para a paz e a segurança internacionais, ainda que, durante a maior parte da Guerra Fria, tais operações tenham sido apenas levemente armadas e funcionado como forças de proteção e de monitoramento.

\section{AS TRANSFORMAÇÕES DAS REGRAS INTERNACIONAIS SOBRE VIOLÊNCIA NA ORDEM MUNDIAL CONTEMPORÂNEA}

A partir da década de 1990, foi possível observar uma crescente expansão desses diferentes conjuntos de regras internacionais. Deslocando

DADOS - Revista de Ciências Sociais, Rio de Janeiro, vol. 61, nº 1, 2018 
ainda mais o tradicional dualismo entre o doméstico e o internacional, esses regimes internacionais individualmente passaram a abarcar um domínio da vida política ainda mais vasto. Ao mesmo tempo, foi possível verificar a maior confluência entre estes diferentes arranjos normativos. Contudo, como já se poderia esperar, as interpretações de tais fenômenos e transformações não foram nem uníssonas, nem homogêneas, ou pacíficas. Alguns estudos apontaram para a constitucionalização do direito e das relações internacionais, destacando a emergência de uma ordem cosmopolita pós-Westphaliana, enquanto outros, adotando uma postura que Jean L. Cohen identificou como "hermenêutica da suspeita" (Cohen, 2012:5), denunciaram as novas tecnologias de poder e formas de excepcionalismo e império, sobretudo no contexto do pós-11 de setembro de 2001 (Cohen, 2012; ver também Brown, 2002; Douzinas, 2007; Duffield, 2007, 2010, 2014; Walker, 2010). Diante da "guerra contra o terror", de Guantánamo Bay e do uso da violência pelas forças lideradas pelos Estados Unidos no Afeganistão e no Iraque, a despeito das decisões do Conselho de Segurança da ONU, a até então hegemônica narrativa liberal de globalização, sociedade civil global e "fim da história" passou a ser crescentemente contestada (Fukuyama, 1992; ver Derrida, 1994, para uma crítica). De acordo com narrativas assentadas numa hermenêutica da suspeita, a era de "intervencionismo liberal" teria chegado ao fim com a declaração unilateral norte-americana de guerra ao terror e as subsequentes invasões do Afeganistão e Iraque (Duffield, 2010:28; Douzinas, 2007).

No entanto, o contexto contemporâneo pós-Guerra Fria é complexo e ambíguo. Ao mesmo tempo em que o humanitarismo liberal intervencionista dos anos 1990 parece ter sido duramente golpeado ou, pelo menos, ressignificado após as reações norte-americanas no pós-11 de setembro de 2001, a emergência de um planeta eletronicamente conectado e sem fronteiras é indissociável da transição de um mundo fordista para um mundo pós-fordista e da nova economia em redes do capitalismo que se consolida na década de 1990. A emergência das assim chamadas "novas guerras", as profundas transformações do nexo entre desenvolvimento e segurança e as novas redes de governança liberal global (Duffield, 2007, 2010 2014), ou mesmo o retorno à tradição da guerra justa a partir de um discurso pós-moderno de "império global" (Bartelson, 2010:82), não significaram o abandono por completo de elementos característicos daquelas narrativas e preocupações liberais solidaristas então hegemônicas na década de 1990; pelo menos, não, no mundo ocidental industrializado do norte (Wheeler, 2000; Brown, 
As Transformações das Regras Internacionais sobre Violência na Ordem Mundial...

2002). Adotando uma postura intermediária em relação aos discursos de um "império" global ou de uma "comunidade" global (Bartelson, 2010:81-88), outras leituras da ordem mundial contemporânea pós-Guerra Fria identificam nas transformações daqueles conjuntos de regras internacionais sobre violência a emergência de um "direito da humanidade" fundado na expansão e confluência do direito internacional humanitário, do direito internacional dos direitos humanos e do direito internacional penal (Teitel, 2011). Outras, ainda, tal como a leitura "pluralista constitucional" de Cohen, sugerem a emergência de uma "ordem mundial dualista" constituída por um "novo regime de soberania", compatível com uma forma de "constitucionalização de baixa intensidade" (Cohen, 2010 e 2012).

Nosso estudo se aproxima dessas posturas intermediárias, mas parte de um referencial teórico distinto, qual seja, o de certo construtivismo de RI. Tal como comentamos na introdução deste trabalho, entendemos que as regras internacionais constituem e expressam o que ReusSmit identificou como a estrutura constitucional da sociedade internacional. Assim, as regras internacionais podem ser interpretadas como expressões mais específicas de tal estrutura constitucional e de seus elementos normativos primários. Aqui, concebemos "segurança" e "soberania" como elementos normativos primários, razão pela qual iremos comentar, a seguir, a redefinição do conceito de segurança e a ressignificação do conceito de soberania, para em seguida passarmos ao comentário de algumas transformações mais específicas dos conjuntos de regras internacionais relativos à violência. Ao fazê-lo, não nos esquecemos do "nexo regras-governo" sugerido por Onuf, assumindo, com este, que o processo de transformação de tais regras é indissociável das relações assimétricas de poder na ordem mundial.

\section{A Redefinição do Conceito de Segurança}

A crescente interdependência entre as sociedades tem alcançado também a dimensão da segurança. Isso é evidente nas discussões sobre a ameaça representada pelos armamentos nucleares, químicos e biológicos, sobre a fuga de refugiados de conflitos domésticos, sobre o crime transnacional, o terrorismo, as crises ambientais e os abusos humanitários. Adicione-se a isso o fato de que o fluxo de mercadorias e informações obteve velocidade e alcance inimagináveis há algumas décadas. Ao mesmo tempo, a crescente rede de regras internacionais que constituem a sociedade internacional passou a limitar significativamente a

DADOS - Revista de Ciências Sociais, Rio de Janeiro, vol. 61, nº 1, 2018 
autonomia dos Estados na esfera da segurança, da mesma forma que em outras áreas da vida internacional. Por sua vez, as chamadas "novas guerras" vêm impondo desafios significativos às tradicionais organizações internacionais, uma vez que estas, em grande medida desenhadas a partir de modelos interestatais, têm que lidar com tais fenômenos caracterizados por uma complexidade política tamanha que escapa à capacidade das gramáticas institucionais estadocêntricas de contenção e regulação dos conflitos e da violência (Duffield, 2014). Além disso, há uma incorporação de questões econômicas, sociais e ambientais na agenda de segurança, em razão, por um lado, de conflitos violentos e situações excepcionais e, por outro lado, da redefinição conceitual de ameaças à vida e do consequente reconhecimento de que ameaças e respostas não mais estão atreladas, exclusiva ou mesmo primariamente, à competência dos militares (Dewitt, 1993). Questões de saúde global, aquecimento global, poluição ambiental, fornecimento de energia e crescimento demográfico são apenas algumas das questões que passaram a ser próprias também da área de segurança, seja em níveis nacional, internacional ou global.

Nesse quadro, o conceito de segurança humana, concebido no Relatório de Desenvolvimento Humano do Programa das Nações Unidas para o Desenvolvimento (PNUD) de 1994, afirmou-se como um marco do processo de ampliação ou extensão do conceito da segurança (PNUD, 1994). E neste processo multidimensional, a segurança vem se estendendo de diferentes formas. Numa delas, o conceito de segurança é estendido de nações a indivíduos. Noutra, a segurança se estende das nações para o sistema internacional e para a biosfera. Há também uma forma em que o conceito incorpora outros tipos de segurança, estendendo-se horizontalmente "do militar para o político, econômico, social, ambiental ou humano" (Rothschild, 1995:57). E, por fim, o conceito é ampliado em termos da "responsabilidade política de garantir a segurança", estendendo-se de Estados soberanos para instituições internacionais, governos regionais ou locais, organizações não governamentais, opinião pública, imprensa, assim como às "forças abstratas da natureza ou do mercado" (idem). De modo geral, a extensão do conceito de segurança envolve as redefinições das fontes de ameaça e dos objetos de referência. Os processos econômicos, ecológicos, sociais e culturais passam a ser vistos como produtores de ameaças. Em contraste com o foco anterior, lançado unicamente sobre as ameaças ao Estado, as ameaças enfrentadas pelos indivíduos, grupos de identida- 
As Transformações das Regras Internacionais sobre Violência na Ordem Mundial...

de, regiões, civilizações ou meio ambiente são, agora, levadas em consideração.

O significado de segurança não é mais restrito à sobrevivência física. Daí, portanto, o surgimento de novos termos neste contexto, como, por exemplo, "segurança alimentar", "segurança ambiental", "segurança da saúde" e "segurança humana". Além disso, na medida em que a Agenda para a Paz de 1995 claramente afirmou que a ONU deveria estar envolvida na prevenção de conflitos e da violência dentro dos Estados, a expansão do conceito de segurança implicou revisões do próprio conceito de tempo. Apesar de a abordagem preventiva das ameaças não ser uma novidade do período pós-Guerra Fria, ela assumiu um lugar central após 1995 e tem sido institucionalizada em níveis governamentais e intergovernamentais. Nesse contexto, novos temas foram tratados no Conselho de Segurança como ameaças à paz e à segurança internacionais, tais como a fome, o desrespeito aos direitos humanos e ao direito humanitário, as crises humanitárias e a falência de Estados. O sistema de segurança coletiva da ONU não apenas foi libertado da paralisia da Guerra Fria, mas encontrou novas formas de atuação, o que consequentemente fez aumentar, num ritmo inimaginável até então, o número de resoluções do Conselho de Segurança baseadas no Capítulo VII. Não por acaso a redefinição do conceito de segurança suscitou também a ressignificação de outro elemento normativo primário da ordem mundial, qual seja, a soberania.

\section{A Ressignificação do Conceito de Soberania}

A expansão do conceito de segurança e a maior amplitude de atuação do Conselho de Segurança da ONU já seriam suficientes para suscitar uma ressignificação do conceito de soberania na ordem mundial contemporânea. Ademais, se pensarmos o significado de cada um daqueles conjuntos de regras internacionais sobre violência para o deslocamento da tradicional geometria política baseada no dualismo inter/nacional, bem como para o reconhecimento do indivíduo como uma questão própria da ordem internacional, é difícil imaginar ou pensar soberania no contexto contemporâneo à luz de sua "concepção absolutista" (Cohen, 2010:263). Por exemplo, o regime internacional dos direitos humanos implica, por definição, uma lógica intervencionista que requer afastamento desta concepção absolutista de soberania. Caso contrário, o holocausto poderia ser resumido a uma questão "estritamente" nacional, enquanto o apartheid poderia ser uma questão 
"exclusivamente" doméstica (Reus-Smit, 2001). Da mesma forma, o direito internacional penal pressupõe uma revisão da questão da autoridade, e, logo, da soberania, na medida em que reconhece, por exemplo, a jurisdição universal em alguns casos de crimes internacionais (Macedo, 2006; Orford, 2011).

No entanto, nem os direitos humanos internacionais, nem o direito internacional penal são imunes à política e às relações assimétricas de poder, as quais, para além de constrangê-los, são constitutivas de tais regimes internacionais (Evans, 2001; Douzinas, 2007; Zolo, 2009). Tal como Onuf nos lembraria, as regras internacionais são indissociáveis das relações assimétricas de superordenação e subordinação, e, com elas, das condições de governo hegemônico, hierárquico e heteronômico que possibilitam e permeiam a própria concepção daquelas regras (Onuf, 1998, 2013a). De fato, e em grande medida, o Tribunal de Nuremberg pode ser visto como uma expressão da justiça dos vencedores (Zolo, 2009), o Conselho de Segurança da ONU pode ser identificado como um exemplo de desigualdade soberana e de hegemonia legalizada (Simpson, 2004), assim como várias outras organizações internacionais do contexto pós-1945 podem ser tidas como expressões institucionais de uma ordem liberal hegemônica no mundo ocidental (Cox, 1983). Afinal, há governo nas e por meio das regras internacionais (Onuf, 1998, 2013a).

Em termos neorrealistas de RI, há quem conceba soberania como um jogo de hipocrisia organizada (Krasner, 1999), caracterizado pela "disjunção entre lógicas de apropriação e lógicas de consequência" (Krasner, 2010:98), em que as regras do jogo perduram porque conseguem plasticamente acomodar os interesses e as lógicas de consequência dos principais atores no contexto mais amplo constituído pelas regras internacionais e suas correlatas lógicas de apropriação. Assim, transformações fundamentais da estrutura de regras vigentes na ordem mundial contemporânea seriam possíveis apenas se e quando houvesse ameaças existenciais aos interesses de segurança dos Estados soberanos mais poderosos, responsáveis últimos pela manutenção ou transformação das regras mais básicas do jogo internacional (Krasner, 2010). Nesse sentido, pressupõe-se a antecedência ontológica, e, com ela, o privilégio causal, destes Estados soberanos mais poderosos em relação tanto aos contextos sociais dos quais fazem parte, como às regras internacionais que intermedeiam as relações entre esses agentes e estruturas. Com Onuf, tal como apontamos na introdu- 
As Transformações das Regras Internacionais sobre Violência na Ordem Mundial...

ção, diferimos deste tipo de análise, mas sem desconsiderar questões assimétricas de poder.

Ademais, o que este tipo de leitura neorrealista não considera, por exemplo, é a geopolítica internacional, colonial, constitutiva do próprio jogo de soberanos (Grovogui, 2002; Keene, 2002; Anghie, 2004; Inayatullah e Blaney, 2004). Historicamente, esta é uma geopolítica que remonta ao problema da diferença colocado quando o mundo europeu de Estados soberanos se encontra com o mundo Ameríndio (Inayatullah e Blaney, 2004), e que, portanto, está tanto associada à constituição colonial do direito internacional nos séculos XV e XVI (Anghie, 2004) e ao chamado standard de "civilização" do século XIX (Gong, 1984), como reverbera até os dias de hoje por meio do racismo cultural reproduzido na lógica de desenvolvimento liberal (Duffield, 2010). Formalmente expressa no artigo 22 do Pacto da Liga das Nações, que estabeleceu o sistema de mandatos e tutela como uma responsabilidade ou "obrigação sagrada da civilização" (Liga das Nações, 1924), a geopolítica internacional colonial parece se expressar contemporaneamente nos traços inscritos no mapeamento feito pelo Tribunal Penal Internacional (TPI) das situações mais graves de violações de direitos humanos no mundo contemporâneo: das dez situações sob investigação no TPI, com exceção daquela da Geórgia, todas as demais envolvem países africanos, a saber, a República Democrática do Congo, Uganda, a República Central Africana, a região de Darfur, no Sudão, o Quênia, a Líbia, a Costa do Marfim, o Mali e, novamente, a República Central Africana ${ }^{18}$.

Numa chave política e conceitual distinta da neorrealista, mas igualmente silentes quanto à origem colonial do jogo de soberanos, outras leituras revisitaram o conceito de soberania no contexto pós-Guerra Fria, repensando o princípio Hobbesiano de proteção e obediência (Schmitt, 2008), agora, em termos de responsabilidade (Deng et al., 1996). Tal como comumente aceita nas relações internacionais, a soberania do Estado é considerada nessas leituras como um princípio fundamental que serve de pilar à ONU e ao direito internacional (Welsh, 2004). No entanto, na esteira da onda liberal solidarista da década de 1990, bem como da ascendência dos direitos humanos e das questões humanitárias ao centro normativo e político da ordem mundial pós-Guerra Fria, a soberania não mais poderia significar ou ser tomada como sinônimo de impunidade ou injustiça, tampouco de indiferença, haja vista o novo lugar do indivíduo nas relações internacionais. Desse

DADOS - Revista de Ciências Sociais, Rio de Janeiro, vol. 61, nº 1, 2018 
modo, no contexto das narrativas liberais, o genocídio de Ruanda, a limpeza étnica nos Bálcãs e as torturas cometidas, décadas antes, durante a ditadura no Chile, não apenas suscitaram, respectivamente, $o$ Tribunal Penal Internacional ad hoc para Ruanda, o Tribunal Penal Internacional ad hoc para ex-Iugoslávia e o caso Pinochet, como, entre outros exemplos que também poderiam ser incluídos aqui, contribuíram para um movimento mais amplo de ressignificação do conceito de soberania à luz dos direitos humanos. A soberania, tradicionalmente concebida como autoridade, passava a ser ressignificada como responsabilidade. Nos termos já citados de Reus-Smit, articulava-se um novo princípio organizacional de soberania, que apontava para o reconhecimento internacional de um novo propósito moral do Estado.

Nesse contexto, em 1999, o então Secretário-Geral da ONU, Kofi Annan, publicou um artigo na revista The Economist intitulado "Two concepts of Sovereignty". Ali, Annan apontou para o processo de ressignificação da soberania do Estado. De um lado, reconheceu o fortalecimento da soberania individual fundada nos direitos humanos e na indivisibilidade da humanidade. De outro lado, afirmou que o Estado deveria ser entendido como um instrumento a serviço de seu povo; e não o contrário (Annan, 1999). O artigo de Annan é sintomático da transformação daqueles conjuntos de regras internacionais sobre violência, sugerindo suas expansões e confluências, mas não sem dificuldades, problemas ou desafios. Ali, o então Secretário-Geral da ONU convocava a comunidade internacional a repensar os termos das chamadas "intervenções humanitárias" à luz da responsabilidade de proteger os direitos humanos mais fundamentais dos indivíduos (Annan, 1999). Dois anos depois, em 2001, a Comissão Internacional sobre Intervenção e Soberania Estatal apresentou seu relatório intitulado "Responsability to Protect"19, propondo, entre outras medidas, a transferência à comunidade internacional em caráter complementar da responsabilidade, originariamente do Estado, de proteger sua população contra o genocídio, os crimes de guerra, os crimes contra humanidade e a limpeza étnica. A responsabilidade internacional de proteger seria, portanto, complementar à responsabilidade do Estado, exigível apenas no caso deste não estar em condições de empenhar-se de modo suficiente para proteger sua população de graves violações de direitos humanos que mencionamos anteriormente. As questões de "prevenção", "alívio" e "reconstrução" também faziam parte desse novo conceito, mas o que mais nos interessa aqui é a questão conceitual central da responsabilidade internacional (Thakur, 2017) ${ }^{20}$. 
As Transformações das Regras Internacionais sobre Violência na Ordem Mundial...

De modo geral, a afirmação internacional deste novo conceito pode ser interpretada, pelo menos formalmente, como a expressão de uma dupla ressignificação do conceito de soberania: de um lado, a soberania deixa de significar exclusivamente autoridade, passando a significar também responsabilidade; e, de outro lado, a soberania deixa de ter seu significado exclusivamente atrelado ao Estado, passando a ter um sentido ligado à comunidade internacional. Assim, o conceito de responsabilidade de proteger nos leva de novo à questão da autoridade internacional (Orford, 2011). O problema da soberania na ordem mundial contemporânea impõe reconhecer a tensão entre, de um lado, a autoridade-responsabilidade do Estado e, de outro lado, a autoridade-responsabilidade do sistema internacional (Walker, 2010). Nos termos de Cohen, tais transformações seriam indícios da emergência de uma ordem mundial dualista, cujo novo regime de soberania redefiniria "as prerrogativas legais dos Estados soberanos" (Cohen, 2012:5). Aqui, lembraríamos, com Reus-Smit, que a soberania do Estado é um elemento normativo primário da estrutura constitucional da sociedade internacional (Reus-Smit, 1997, 1999 e 2001). O que significa dizer que tanto a transformação desta estrutura implica a redefinição daquele elemento, quanto a ressignificação deste implica a reconstrução daquela. Soberania é uma "instituição" internacional (Onuf, 1998:62). Dessa forma, tal como nos sugere Onuf, sua reconstrução tanto implicaria a transformação das regras internacionais que possibilitam o contexto social dentro do qual ela, soberania, ganha todo e qualquer significado político, quanto seria indissociável das relações assimétricas de superordenação e subordinação que constituem as condições de governo hierárquico, hegemônico e heteronômico por meio de tais regras (Onuf, 1998, 2013a).

\section{A Expansão e Confluência das Regras Internacionais sobre Violência}

Desde a década de 1990, as práticas humanitárias têm se expandido significativamente. Elas passaram a se preocupar com as origens e causas da violência, incluindo-se aí "a cultura da violência, a falta de respeito aos direitos humanos e a ausência de instituições democráticas" (Barnett, 2011:3). As práticas humanitárias não seriam mais apenas direcionadas a situações de emergência, estendendo-se também à estrutura política e social da sociedade. As formas e políticas do Estado passariam a ser parte da agenda. Nesse sentido, a governança democrática seria cada vez mais naturalizada como condição de possibilidade dos 
direitos humanos, enquanto a democracia, caracterizada em termos liberais, seria transformada em uma regra supostamente universal sobre a forma de organização política (Zanotti, 2005). A associação entre democracia e paz iria se tornar uma parte crucial do discurso de líderes políticos e acadêmicos no mundo pós-Guerra Fria (Doyle, 1996). Num contexto em que o sistema capitalista tornou-se ainda mais excludente, em que a desregulamentação do mercado afirmou-se como um fenômeno global e a competência dos Estados nacionais foi atenuada, a liberalização econômica passou a ser considerada insuficiente e o desenvolvimento, cada vez mais próximo ou mesmo indissociável das questões de segurança (Duffield, 2007, 2010, 2014). Mais especificamente, o subdesenvolvimento passou a ser associado às causas das assim chamadas "novas guerras", e, consequentemente, aos problemas de paz e segurança internacionais, o que justificou novas políticas e práticas internacionais de resolução de conflitos e reconstrução de Estados e sociedades. Visando a prevenção de conflitos e a paz liberal, tais práticas e políticas internacionais passaram a implementar uma nova agenda de transformação social mediante o incentivo à democratização, às instituições pluralistas e à reconstrução das sociedades e valores locais à imagem liberal das novas redes de governança global (Duffield, 2014).

Nessas condições, as práticas humanitárias seriam institucionalizadas e suas organizações e operações, racionalizadas. Ao mesmo tempo, a participação das agências humanitárias no debate político e nas operações militares seria muitas vezes identificada como uma fonte de risco para suas operações, na medida em que poderia causar a perda do manto da neutralidade e da virtude universal. Barnett chama a atenção para a crescente governança do humanitarismo, a qual se realiza de maneiras institucionalizadas, públicas e hierarquizadas (Barnett, 2011). Torna-se por isso mais difícil afirmar a autonomia da lógica humanitária (Barnett, 2011; Kennedy, 2006). Ao longo das últimas décadas, diferentes atores, como militares, agências de desenvolvimento e o próprio aparato do Estado, incorporaram o discurso e as práticas humanitárias. O humanitarismo tornou-se parte da governança global, desenvolvendo-se uma íntima relação entre humanitarismo, poder e diferentes formas de influência sobre as sociedades nacionais e as esferas internacionais. Consequentemente, tornou-se cada vez mais difícil sustentar a separação entre aqueles que governam e aqueles que mantêm a responsabilidade de governar (Kennedy, 2006). O aumento da capacidade de contribuir e ajudar a aliviar crises humanitárias, dadas 
As Transformações das Regras Internacionais sobre Violência na Ordem Mundial...

as melhorias logísticas e as novas tecnologias de transporte e de comunicação, também permitiu que as diferentes agências e organizações se tornassem multidimensionais, participassem de operações complexas e não mais pudessem manter suas distinções funcionais (Kalshoven e Zegveld, 2001).

É possível observar um contínuo processo de expansão e confluência das regras internacionais sobre violência no pós-Guerra Fria. Em que pesem as ambiguidades, tensões e limites inerentes a tal processo, a transformação dos regimes internacionais no mundo depois de 1989 possibilitou a emergência pelo menos até o final da década de 1990 de novas regras e práticas internacionais, como as chamadas "intervenções humanitárias" (Dunne e Wheeler, 1999; Wheeler, 2000; Brown, 2002). ${ }^{21}$ Tendo tido início com a ação internacional para proteger a população curda no norte do Iraque em 1991, as intervenções humanitárias tinham como cerne, pelo menos para alguns, a preocupação de "salvar estranhos" (Wheeler, 2000); isto é, proteger internacionalmente indivíduos em situações de graves crises humanitárias e violações de direitos humanos, independentemente de quais fossem suas nacionalidades. Como o próprio nome já sugeriria, estas regras e práticas humanitárias visavam proteger internacionalmente os indivíduos mesmo que a expensas da tradicional regra internacional de não intervenção fundamentalmente atrelada à soberania. Contudo, casos como os de Ruanda em 1994, de Srebrenica em 1995 e os de Kosovo e Timor Leste no final da década de 1990 já colocavam em questão a seletividade, a celeridade, o militarismo, as políticas e outras condições de possibilidade de tais intervenções (Annan, 1999; Brown, 2002). Leituras críticas dos direitos humanos, do humanitarismo e das intervenções humanitárias chamaram a atenção para suas fundações e heranças coloniais, assinalando as continuidades de um padrão de civilização constitutivo do mundo moderno e das subjetividades individuais e coletivas moldadas à sua imagem (Mutua, 2001; Keene, 2002; Inayatullah e Blaney, 2004; Anghie, 2004; Douzinas, 2007; Walker, 2010).

Não mais à sombra do equilíbrio do terror, a ordem pós-Guerra Fria viu eclodir inúmeros conflitos não internacionais e novas relações de violência. Somados à economia mundial pós-fordista, às mais distintas tensões e questões de identidade, aos avanços tecnológicos, sobretudo no que se refere aos meios de transporte e de comunicação, e às profundas transformações da governança global num mundo de relações agora cada vez mais não territoriais e poliárquicas (Duffield, 2014), os

DADOS - Revista de Ciências Sociais, Rio de Janeiro, vol. 61, nº 1, 2018 
novos fenômenos de conflito e violência colocaram em xeque muitas das premissas e fundações sobre as quais se sustentavam o humanitarismo e o direito internacional humanitário. A natureza das guerras civis na década de 1990 e o fluxo das informações sobre os conflitos domésticos, por exemplo, provocaram o questionamento das distinções entre guerra e paz, e entre combatentes e não combatentes. Contudo, em que pesem os problemas e limites de suas fundações e premissas, tal como expostos pelas "novas guerras" (Kaldor, 2007; Duffield, 2014), o direito internacional humanitário, suas distinções fundamentais e as correlatas proteções humanitárias ainda se fariam presentes e relevantes nos debates sobre violência e legalidade no mundo contemporâneo. Os ataques ao World Trade Center e ao Pentágono e a reação norte-americana a tais fatos recolocaram em evidência a relevância de proteções humanitárias, assim como alguns dos desafios contemporâneos a tais regras internacionais.

A definição da "guerra contra o terror" como um conflito ao mesmo tempo "não internacional" e "transnacional" e a construção do inimigo como um "combatente ilegal", por exemplo, apontaram tanto para os limites do direito internacional humanitário como para sua relevância no que tange à proteção de prisioneiros de guerra. No contexto imediatamente posterior a 11 de setembro de 2001, o Departamento de Defesa dos EUA havia solicitado ao Departamento de Justiça suas opiniões jurídicas sobre a aplicação das Convenções de Genebra de 1949 aos procedimentos de detenção e julgamento de membros da $\mathrm{Al}$ Qaeda e da milícia Talibã. Em 9 e 22 de janeiro de 2002, o Departamento de Justiça norte-americano apresentou versões do memorando que serviria para justificar a não aplicação das Convenções de Genebra aos "combatentes ilegais" (Yoo e Delabunty, 2005; Bybee, 2005). Assim definidos, esses indivíduos não teriam direito às proteções garantidas a prisioneiros de guerra e seriam detidos em Guantánamo Bay por tempo indeterminado (Butler, 2004). Nas construções de suas respectivas argumentações jurídicas, ambos os memorandos concluíram que as Convenções de Genebra não se aplicavam a "um conflito armado entre um Estado-nação e uma organização terrorista transnacional" (Bybee, 2005:84-88; Yoo e Delabunty, 2005:42-47).

Dessa maneira, a "guerra contra o terror" introduziu um sério desafio ao direito internacional humanitário (ICRC, 2003, 2007, 2011, 2015), qual seja, o de reconciliar suas premissas racionalistas (Sassòli e Bouvier, 1999:68) com a natureza de um conflito cuja estrutura moral 
As Transformações das Regras Internacionais sobre Violência na Ordem Mundial...

é análoga à de guerra justa (Schmitt, 2003; Ulmen, 2007). Além disso, a "guerra contra o terror" tornou ainda mais evidente o excepcionalismo unilateral norte-americano, e, assim, pôde ser relida também como expressão de um "império global" (Hardt e Negri, 2000; Jabri, 2007; Bartelson, 2010). De outro modo, ela também pôde ser relida como a expressão de uma profunda ressignificação da guerra no âmbito das transformações da política global no contexto da modernidade tardia (Jabri, 2007). Com a emergência de uma "matriz global de guerra" os conflitos passam a ser incontidos e sem limites, provocando, consequentemente, o desmantelamento das concepções tradicionais das fronteiras do Estado e das regras internacionais a elas associadas (Jabri, 2007:8). Uma característica central desta nova matriz global de guerra é sua natureza transnacional, implicando, para além dos Estados, outros diversos atores não estatais e uma complexa assemblagem de relações que possuem a capacidade de transcender e desarticular o dualismo inter/nacional que tradicionalmente enforma e sustenta a arquitetura daquelas regras internacionais sobre violência (Jabri, 2007). Ademais, a natureza global desta nova matriz implica o redesenho de um teatro de guerra, agora, planetário e "concebido em termos da humanidade em geral" (Jabri, 2007:31). No contexto contemporâneo da modernidade tardia, tal como nos sugere Vivienne Jabri, há "o surgimento de uma subjetividade soberana global que considera o global dentro de sua esfera de operações" (Jabri, 2007:8).

Nesse sentido, o regime do direito internacional penal também aponta para a emergência de uma autoridade global cujo poder de ditar o direito se fundamenta na humanidade (Teitel, 2011; Orford, 2011; Douzinas, 2007) e na existência de direitos humanos fundamentais baseados numa ordem normativa "metanacional" (Cassese 2003a:70). O renascimento deste regime internacional no contexto do final da Guerra Fria foi intimamente associado à transformação do regime de segurança coletiva e ao seu maior entrelaçamento com os regimes de direitos humanos e de direito internacional humanitário, assim como à ampliação do conceito de segurança e à ressignificação da soberania. Ele expressou, ademais, a revisão do tradicional dualismo inter/nacional e o novo lugar do indivíduo nas relações internacionais (Brown e Ainley, 2005). Por exemplo, reconhecendo as implicações de graves violações de direitos humanos para a paz e a segurança internacionais, o Conselho de Segurança constituiu os TPIs ad hoc para ex-Iugoslávia, em 1993, e para Ruanda, em 1994, recolocando em marcha o projeto de um TPI permanente que, vislumbrado desde o final da Primeira Guer-

DADOS - Revista de Ciências Sociais, Rio de Janeiro, vol. 61, nº 1, 2018 
ra Mundial, seria normativamente concebido em 1998, em Roma, e institucionalmente concretizado em 2002, em Haia (Sands, 2003).

Neste processo específico, a atuação da única superpotência do mundo pós-Guerra Fria, os EUA, foi determinante para a constituição de um TPI que não fosse completamente autônomo e que não tivesse jurisdição universal e compulsória, o que ameaçaria o lugar privilegiado, não apenas em termos geopolíticos, mas também jurídicos, daquele membro permanente do Conselho de Segurança (Wippman, 2004). Um rastro político e jurídico de tais interesses e atuação dos EUA durante o processo de negociação do tratado de Roma foi a formalização da possibilidade de o Conselho de Segurança submeter um caso ao TPI com base na sua autoridade fundamentada no Capítulo VII da Carta da ONU (Simpson, 2004, 2007; Sands, 2003; Wippman, 2004). Noutros termos, a hegemonia norte-americana legalizou-se por meio da constituição de uma forma jurídica de "poder institucional" (Barnett e Duvall, 2005a:51) 22. Constituiu-se assim uma instituição global que formaliza "uma distribuição assimétrica de benefícios" (Barnett e Duvall, 2005a:64), não apenas beneficiando os EUA, como também os demais membros permanentes do Conselho de Segurança da ONU.

O atual caso perante o TPI do Chefe de Estado do Sudão é um bom exemplo não apenas do processo de expansão e confluência das regras internacionais de violência, como, também, das relações de poder e de governo que permeiam tais regras internacionais. Em setembro de 2004, por meio da Resolução 1564, e a pedidos do Conselho de Direitos Humanos e do Secretário-Geral da ONU, o Conselho de Segurança solicitou que o Secretário Geral estabelecesse uma comissão internacional com a finalidade de investigar as denúncias de violações do direito internacional humanitário e dos direitos humanos em Darfur, no Sudão. Assim, Kofi Annan, o então Secretário Geral, estabeleceu a Comissão Internacional de Inquérito sobre Darfur, cujo relatório apontou casos de crimes contra a humanidade e crimes de guerra, bem como recomendou que o Conselho de Segurança encaminhasse o caso para o TPI (Oette, 2010). Em março de 2005, por meio de sua Resolução 1593, o Conselho de Segurança acatou a recomendação da Comissão e indicou o caso de Darfur ao TPI, de acordo com sua prerrogativa estabelecida pelo artigo 13 do Estatuto de Roma (TPI, 2005). Foi a primeira vez que a jurisdição do TPI foi acionada por meio de uma solicitação do Conselho de Segurança da ONU (Böckenförd, 2010). 
As Transformações das Regras Internacionais sobre Violência na Ordem Mundial...

Em junho de 2005, iniciaram-se as investigações da situação de Darfur no TPI, que resultaram na instauração de cinco processos contra oficiais do governo sudanês, incluindo-se aí o caso do Chefe de Estado, em exercício, do Sudão, Omar Al Bashir. Neste caso específico, mesmo contra a vontade soberana do Sudão, que, diga-se de passagem, não ratificou o tratado de Roma, busca-se a responsabilização penal internacional do representante do Estado soberano do Sudão, pela comissão de crimes contra humanidade, crimes de guerra e genocídio (TPI, 2005). Apesar de não ter ratificado ou aderido ao Estatuto de Roma, o Sudão estaria obrigado a cooperar e a submeter-se à jurisdição do TPI em razão da determinação da Resolução 1593 do Conselho de Segurança da ONU, dado o significado jurídico que tal resolução tem, seja em termos do direito internacional consuetudinário, seja em termos das obrigações internacionais advindas do tratado de São Francisco de 1945 ao qual o Sudão aderiu em 1956, seja em razão de continuidades daquela geopolítica internacional colonial. Note-se, porém, que o mesmo não aconteceria com um membro permanente do Conselho de Segurança da ONU que, dotado de poder de veto permanente, não tivesse ratificado ou aderido por vontade própria ao Estatuto de Roma, tal como os EUA, por exemplo.

\section{CONCLUSÃO}

O caso Al Bashir exemplifica bem o "nexo regras-governo" sugerido por Onuf, na medida em que o regime internacional do TPI, uma vez legitimado pelos regimes de direitos humanos e direito internacional humanitário, e acionado pelo Conselho de Segurança da ONU, impôs-se ao Estado soberano do Sudão heteronômica, hegemônica e hierarquicamente. Ele é sintomático das relações político-sociais assimétricas de super e subordinação que permeiam as regras internacionais em geral, e, logo, aquelas cujas transformações estudamos aqui. Ontologicamente, seguindo o construtivismo de Onuf, concebemos as regras internacionais estudadas aqui como regras sociais indissociáveis tanto do processo de co-constituição entre agentes, instituições e estruturas sociais como das condições de governo hierárquico, hegemônico e heteronômico que condicionam e são condicionadas por este processo e por aquelas regras. Nestes termos, assumimos que há governo nas e por meio das regras sociais; e vice-versa.

No entanto, seguindo Onuf novamente, optamos por manter analiticamente separados o modelo de prática de regras e o modelo de prática

DADOS - Revista de Ciências Sociais, Rio de Janeiro, vol. 61, nº 1, 2018 
de poderes, privilegiando o primeiro, mesmo que insistindo ontologicamente na indissociabilidade de ambos. Dessa forma, sugerimos que, seja no caso Al Bashir, seja a relação entre o TPI e o Conselho de Segurança legalizada em Roma, seja a hegemonia legalizada do Conselho de Segurança, seja a justiça dos vencedores de Nuremberg, ou o padrão de civilização constitutivo tanto do artigo 22 da Liga das Nações como das políticas liberais de desenvolvimento e das políticas e práticas de reconstrução de Estados em prol da paz liberal, todos esses exemplos pressupõem regras, relações e (trans)formações sociais condicionadas e condicionantes de diferentes relações de poder.

As transformações políticas e sociais analisadas neste artigo suscitam novos debates sobre violência. Após os acontecimentos de 11 de setembro de 2001, não só a "guerra contra o terror", o retorno à tradição da guerra justa, o excepcionalismo unilateral dos EUA e a nova centralidade da segurança nacional, mas também o recrudescimento das políticas de identidade e de fronteiras e o retorno da geopolítica são alguns elementos constitutivos do bastante complexo e ambíguo contexto da ordem mundial contemporânea. Entre outros fenômenos, eles atestam a plasticidade da soberania, cujo significado vem sendo transformado nas últimas décadas, bem como impõem diferentes desafios aos regimes internacionais estudados neste trabalho. Mais recentemente, algumas políticas e práticas associadas ao liberal solidarismo e intervencionismo do período imediatamente posterior ao final da Guerra Fria vêm sendo reexaminadas criticamente não somente como expressões de relações de poder hegemônicas e hierárquicas, mas como heranças, rastros ou continuidades de padrões de civilização e geopolíticas internacionais coloniais constitutivas do mundo moderno e das subjetividades coletivas e individuais modeladas à sua imagem e semelhança.

Num contexto em que o subdesenvolvimento passou a ser concebido como causa de conflito e guerra, em que o sistema capitalista pós-fordista tornou-se mais e mais excludente e necropolítico, em que a desregulamentação do mercado afirmou-se como um fenômeno global, e a competência dos Estados nacionais foi atenuada num mundo de relações cada vez mais não territoriais e poliárquicas, o dualismo inter/nacional que tradicionalmente sustentava a arquitetura das regras estudadas neste trabalho foi seriamente desafiado. Em nome da prevenção de conflitos e da paz liberal, práticas e políticas internacionais passaram a pôr em execução uma nova agenda de reconstrução de Estados e sociedades, buscando transformar comunidades e valores locais a par- 
As Transformações das Regras Internacionais sobre Violência na Ordem Mundial...

tir de ideias e ideais liberais provenientes do mundo pós-fordista ocidental do Norte. As transformações das regras internacionais estudadas neste artigo tornaram possíveis uma prática política internacional de subjetivação e assujeitamento coletivo e individual, que, incongruente com a regra de não intervenção, provocou a ressignificação do conceito de soberania.

Parece-nos fundamental compreender como chegamos até aqui, e, consequentemente, como as regras internacionais sobre violência têm sido transformadas e reconstruídas. Este artigo buscou fazer esse mapeamento e contextualização, chamando a atenção para as transformações dos conjuntos de regras internacionais e algumas de suas premissas que vêm tomando lugar nos contextos pós-Guerra Fria e pós-11 de setembro de 2001. Essas transformações são sintomáticas de reconstruções fundamentais da ordem política mundial e de sua estrutura constitucional. Ademais, elas são constitutivas da contextura políticosocial dentro da qual qualquer pensamento, ou posicionamento, acerca da violência no mundo deve e pode se dar.

(Recebido para publicação em 5 de Fevereiro de 2016)

(Reapresentado em 31 de Maio de 2017)

(Aprovado em 22 de Agosto de 2017)

DADOS - Revista de Ciências Sociais, Rio de Janeiro, vol. 61, nº 1, 2018 


\section{Monica Herz e Roberto Vilchez Yamato}

\section{NOTAS}

1. Doravante, usaremos "RI" quando nos referirmos à disciplina de Relações Internacionais; continuaremos utilizando "relações internacionais", por extenso e em letras minúsculas, quando estivermos nos referindo aos fenômenos que são objeto de estudo de RI.

2. Para uma releitura crítica, neorrealista (de RI), desta forma política Westphaliana, ver Krasner (1999 e 2010).

3. "Regimes internacionais são definidos como princípios, normas, regras e procedimentos decisórios em torno dos quais as expectativas do ator convergem numa dada área temática" (Krasner, 1983a:1, ênfase nossa). Para outras definições de regime internacional, ver, por exemplo, Krasner (1983b), Rittberger (1993) e Hasenclever, Mayer e Rittberger (1997).

4. “Instituições fundamentais são conjuntos de normas, regras e princípios prescritivos que especificam como os Estados legítimos "devem" resolver seus conflitos, coordenar suas relações, e facilitar a coexistência" (Reus-Smit, 1999:34, ênfase acrescida).

5. 'Normas de justiça procedimental pura especificam os procedimentos corretos que Estados "legítimos" ou "bons" empregam, interna e externamente, para formular regras básicas de conduta interna e externa" (Reus-Smit, 1999:32, ênfase acrescida). A diferenciação entre regimes internacionais, instituições fundamentais e estrutura constitucional alude ou pode ser repensada em relação à literatura de RI que diferencia instituições primárias e secundárias, específicas e fundamentais ou fundacionais. Não iremos discutir esta literatura aqui, dado o espaço limitado que temos. No entanto, sugerimos que leitores interessados vejam, por exemplo, Buzan (2004, particularmente Cap. 6:161-204); Linklater e Suganami (2006, particularmente Cap. 2:43-80); Holsti (2004, particularmente Cap.1:1-27).

6. Nesse sentido, cumpre destacar que Onuf não diferencia regras de normas (Onuf, 2013b:135), considerando princípios, normas, regras e procedimentos decisórios como diferentes "categorias de regras" (Onuf, 1998:70). Dado o espaço limitado que temos, não iremos discutir tais diferenciações, tampouco questionar este aspecto da definição de regras de Onuf.

7. “Como reconhecíveis padrões de regras e práticas relacionadas, instituições fazem das pessoas agentes e constituem um ambiente dentro do qual os agentes se conduzem racionalmente" (Onuf, 1998:61).

8. A concepção de regra de Onuf é bastante rica e complexa. De um lado, ela é influenciada pela concepção anglo-saxã da filosofia da linguagem ordinária, mais especificamente pelas teorias de ato de fala de Austin e Searle. De outro lado, ela é influenciada pela concepção positivista do direito, baseada em regras, e pela concepção mais processual do direito internacional, tal como na chamada Escola de Yale e no trabalho de Richard Falk. Não podemos aprofundar tais comentários aqui, mas sugerimos aos leitores interessados verem, por exemplo, Onuf (2013a:66-95; 2008), Wind (2001) e Sinclair (2010).

9. “Hegemonia refere-se à promulgação e manipulação de princípios e instruções por meio dos quais atores superordenados monopolizam o significado que os atores subordinados passam a absorver passivamente" (Onuf, 2013a:209). 
As Transformações das Regras Internacionais sobre Violência na Ordem Mundial...

10. 'Hierarquia é o paradigma de governo mais intimamente associado a Weber porque, como um arranjo de regras diretivas, é imediatamente reconhecível como burocracia. As relações de bureaux, ou funções [offices], formam o padrão típico de superordenação e subordinação, mas sempre em posições sociais, de modo que cada função [office] é tanto subordinado àquelas acima dela como superordenada em relação àquelas abaixo dela" (Onuf, 2013a:211).

11. Aqui, Onuf se distancia de Weber, aproximando-se de Kant e sua releitura da relação (aporética) entre autonomia e heteronomia. (Onuf, 2013a:212-219). Ele explica: 'Se anarquia é uma condição de governo não relacionada a quaisquer intenções do agente, então as relações internacionais não são anarquia. Nós precisamos de outro termo para indicar a forma de governo em que agentes pretendem que sejam governados por aquilo que parecem ser consequências não intencionais do exercício de seus direitos. Heteronomia é um melhor termo. Agentes autônomos agem livremente, enquanto agentes heterônomos não podem agir livremente. Ambos os termos se referem a agentes, e não à sociedade. A partir de uma perspectiva construtivista, no entanto, agentes são sempre autônomos, mas a autonomia deles é sempre limitada pela autonomia (limitada) de outros agentes. O exercício da autonomia faz da heteronomia uma condição social que, os agentes aceitam como uma consequência aparentemente não intencional de suas escolhas autônomas, individuais" (Onuf, 1998:77).

12. O ponto aqui poderia ser resumido com as seguintes palavras de Eduardo Viveiros de Castro, acrescidas de um enxerto: "Em sentido geral, a sociedade [política] é uma condição universal da vida humana" (Viveiros de Castro, 2011:297); a "política" enxertada aqui sendo o rastro do paradigma do Herrschaft relido por Onuf.

13. Nesse sentido, ele enumera alguns pontos desta relação: "1. Agentes têm poderes, poderes produzem regras e regras aumentam poderes; 2 . Agentes usam poderes, regras e habilidades para produzir bens; 3 . Regras, habilidades e bens relacionados constituem um campo de objetos que um agente observador poderia descrever como uma prática; 4 . Padrões de prática constituem a estrutura social; 5 . Observar tais padrões (a atividade de teorizar) transforma estruturas em instituições ao lhes dar conteúdo normativo (conforme 1); 6. Instituições são assemblagens de regras que impõem limites práticos aos agentes e ao exercício de seus poderes" (Onuf, 2013b:135-136).

14. O qual prescreve que a ajuda deve ser prestada aos que necessitam.

15. O qual prescreve que a ajuda deve ser prestada de forma neutra, ou seja, sem privilegiar nenhum dos lados de um conflito.

16. O qual prescreve que as organizações que prestam ajuda humanitária não devem depender ou estar vinculadas a qualquer parte de um conflito.

17. Nós não enfocamos ou analisamos o conceito de segurança nacional neste trabalho.

18. Nesse sentido, ver: https:/ /www.icc-cpi.int/, último acesso em 27.05.2017.

19. Em 2000, foi criado, sob os auspícios do governo canadense, o International Commission on Intervention and State-Sovereignty (ICISS), presidido por Gareth Evans e por Mohamed Sahnou. O relatório "Responsability to Protect" foi lançado em seguida e tornou-se uma referência no debate sobre o assunto. O princípio foi aplicado, pela primeira vez, pelo Conselho de Segurança da ONU na sua resolução sobre Darfur.

20. Em 2004, o High-level Panel on Threats, Challenges and Change da ONU publicou um relatório, intitulado "A More Secure World: Our Shared Responsibility", endossando tal

DADOS - Revista de Ciências Sociais, Rio de Janeiro, vol. 61, nº 1, 2018 


\section{Monica Herz e Roberto Vilchez Yamato}

responsabilidade coletiva internacional. Finalmente, em 2005, o relatório "In Larger Freedom", produzido pelo então Secretário-Geral da ONU, Kofi Annan, endossou o conceito de responsabilidade de proteger e recebeu suporte unânime da Cúpula Mundial das Nações Unidas realizada naquele mesmo ano.

21. No que se refere à confluência entre o regime de segurança coletiva e o regime de direitos humanos, cumpre recordar que as resoluções do Conselho de Segurança da ONU com relação ao regime do apartheid sul-africano foram um divisor de águas na história de tal associação, uma vez que reconheceram, pela primeira vez, o desrespeito aos direitos humanos como uma ameaça à paz e segurança internacionais.

22. De acordo com estes autores, o poder institucional se dá por meio de regras e instituições e implica o controle indireto de uns atores sobre outros (Barnett e Duvall, 2005:51). 
As Transformações das Regras Internacionais sobre Violência na Ordem Mundial...

\section{REFERÊNCIAS BIBLIOGRÁFICAS}

ALSTON, Philip; GOODMAN, Ryan. (2013), International Human Rights: Text and Materials. Oxford, Oxford University Press.

ANGHIE, Antony. (2004), Imperialism, Sovereignty and the Making of International Law. Cambridge, Cambridge University Press.

ANNAN, Kofi. (1999), "Two Concepts of Sovereignty". The Economist. Disponível em http:/ / www.economist.com/node/324795\#print.

ARENDT, Hannah. (1999), Eichmann em Jerusalém: Um Relato sobre a Banalidade do Mal. São Paulo, Companhia das Letras.

• (2011), Origens do Totalitarismo. São Paulo, Companhia das Letras.

BALIBAR, Étienne. (2004), We, the People of Europe? Reflections on Transnational Citizenship. Princeton/Oxford, Princeton University Press.

BARNETT, Michael. (2011), Empire of Humanity. Ithaca, Cornell University Press.

BARNETT, Michael; DUVALL, Raymond. (2005a), "Power in International Politics". International Organization, vol. 59, no 1, pp. 39-75.

(2005b), "Power in Global Governance", in M. Barnett; R. Duvall (eds.), Power in Global Governance. Cambridge, Cambridge University Press, pp. 1-32.

BARTELSON, Jens. (1998), "Second Natures: Is the State Identical with Itself?”. European Journal of International Relations, vol. 4, no 3, pp. 295-326.

. (2010), "Double Binds: Sovereignty and the Just War Tradition", in H. Kalmo; Q. Skinner (eds.), Sovereignty in Fragments: The Past, Present and Future of a Contested Concept. Cambridge, Cambridge University Press, pp. 81-95.

BERMAN, Nathaniel. (2004), "Privileging Combat? Contemporary Conflict and the Legal Construction of War". Columbia Journal of Transnational Law, vol. 43, no1, pp. 1-72.

BLIX, Hans. (1978), “Area Bombardment: Rules and Reasons". British Yearbook of International Law, vol. 49, no 1, pp. 31-69.

BOBBIO, Norberto. (1992), A Era dos Direitos. Rio de Janeiro, Editora Campus.

BÖCKENFÖRD, Markus. (2010), "Sudan". Max Planck Encyclopedia of Public International Law. Disponível em http://opil.ouplaw.com/view/10.1093/law:epil/ 9780199231690/law-9780199231690-e1360?rskey=yOA45W\&result=1\&prd=EPIL Acesso em 28/5/2017.

BRODY, Reed; RATNER, Michael (eds.). (2000), The Pinochet Papers: The Case of Augusto Pinochet in Spain and Britain. London, Kluwer Law International.

BROWN, Chris. (2002), Sovereignty, Rights and Justice: International Political Theory Today. Cambridge, Polity.

BROWN, Chris; AINLEY, Kirsten. (2005), Understanding International Relations. London, Palgrave.

BULL, Hedley. (2002), The Anarchical Society: A Study of Order in World Politics. New York, Palgrave.

DADOS - Revista de Ciências Sociais, Rio de Janeiro, vol. 61, n 1, 2018 


\section{Monica Herz e Roberto Vilchez Yamato}

BUTLER, Judith. (2004), Precarious Life: The Powers of Mourning and Violence. London/New York, Verso.

BUZAN, Barry. (2004), From International to World Society? English School Theory and the Social Structure of Globalisation. Cambridge, Cambridge University Press.

. (2014), An Introduction to the English School of International Relations. Cambridge, Polity.

BYBEE, Jay S. (2005), "Memorandum to Alberto R. Gonzales”, in K. J. Greenberg; J. L. Dratel (eds.), The Torture Papers: The Road to Abu Ghraib. Cambridge, Cambridge University Press, pp. 81-117.

BYERS, Michael. (2007), A Lei da Guerra: Direito Internacional e Conflito Armado. Rio de Janeiro, Record.

CASSESE, Antonio. (2001), International Law. Oxford, Oxford University Press.

(2003a), International Criminal Law. Cambridge, Cambridge University Press.

CASSESE, Antonio. (2003b), "International Criminal Law”, in M. Evans (ed.) International Law. Oxford, Oxford University Press, pp.721-756.

CLAUDE, Inis L. (1962), Power and International Relations. New York, Random House.

(1984), Swords into Plowshares: The Problems and Process of International Organization. New York, Random House.

COHEN, Jean L. (2010), "Sovereignty in the Context of Globalization: A Constitutional Pluralist Perspective", in S. Besson; J. Tasioulas (eds.), The Philosophy of International Law. Oxford, Oxford University Press, pp. 261-280.

. (2012), Globalization and Sovereignty: Rethinking Legality, Legitimacy, and Constitutionalism. Cambridge, Cambridge University Press.

COX, Robert W. (1983), “Gramsci, Hegemony and International Relations: An Essay in Method". Millennium: Journal of International Studies, vol. 12, no 2, pp. 162-175.

CRAWFORD, James; OLLESON, Simon. (2003), “The Nature and Forms of International Responsibility", in M. D. Evans (ed.), International Law. Oxford, Oxford University Press, pp. 445-472.

DENG, Francis M. et al. (1996), Sovereignty as Responsibility: Conflict Management in Africa. Washington, DC, The Brookings Institution.

DERRIDA, Jacques. (1994), Specters of Marx: The State of the Debt, the Work of Mourning and the New International. New York/London, Routledge.

DEWITT, David. (1994), "Introduction: The New Global Order and the Challenges of International Security", in D. Dewitt; D. Haglund; J. Kirton (eds.), Building a New Global Order: Emerging Trends in International Security. Oxford, Oxford University Press, pp. 1-10.

DONNELLY, Jack. (2003), Universal Human Rights in Theory E Practice. Ithaca/London, Cornell University Press.

(2007), International Human Rights. Boulder, Westview Press.

DOUZINAS, Costas. (2007), Human Rights and Empire: The Political Philosophy of Cosmopolitanism. New York/London, Routledge. 
As Transformações das Regras Internacionais sobre Violência na Ordem Mundial...

DOYLE, Michael W. (1996), "Kant, Liberal Legacies and Foreign Affairs", in M. Brown, S. Lynn-Jones and S. Miller (eds.), Debating the Democratic Peace. Cambridge, Mass., MIT Press, pp. 3-57.

DUFFIELD, Mark. (2007), Development, Security and Unending War: Governing the World of Peoples. Cambridge, Polity.

. (2010), "The Development-Security Nexus in Historical Perspective: Governing the World of Peoples", in J. S. Sörensen (ed.), Challenging the Aid Paradigm: Western Currents and Asian Alternatives. New York, Palgrave Macmillan, pp. 25-46.

(2014), Global Governance and the New Wars: The Merging of Development and Security. London/New York, Zed Books.

DUNNE, Tim; WHEELER, Nicholas J. (eds.). (1999), Human Rights in Global Politics. Cambridge, Cambridge University Press.

EVANS, Tony. (2001), The Politics of Human Rights: A Global Perspective. London/Sterling, Pluto Press.

FORSYTHE, David P. (2006), Human Rights in International Relations. Cambridge, Cambridge University Press.

FUKUYAMA, Francis. (1992), The End of History and the Last Man. New York, The Free Press.

GALLI, Carlo. (2010) Political Spaces and Global War. Minneapolis, University of Minnesota Press.

. (2015), Janus's Gaze: Essays on Carl Schmitt. Durham/London, Duke University Press.

GIDDENS, Anthony. (1985), The Nation-State and Violence: Volume Two of A Contemporary Critique of Historical Materialism. Berkeley/Los Angeles, University of California Press.

GONG, Gerrit W. (1984), The Standard of "Civilization" in International Society. Oxford, Clarendon Press.

GRAY, Christine. (2008), "The Charter Limitations on the Use of Force: Theory and Practice", in V. Lowe; A. Roberts; J. Welsh; D. Zaum (eds.), The United Nations Security Council and War: The Evolution of Thought and Practice since 1945. Oxford, Oxford University Press, pp. 86-98.

GROVOGUI, Siba N. (2002), "Regimes of Sovereignty: International Morality and the African Condition". European Journal of International Relations, vol. 8, no 3, pp. 315-338.

GUZZINI, Stefano. (2013), Power, Realism and Constructivism. London/New York, Routledge.

HARDT, Michael; NEGRI, Antonio. (2000), Empire. Cambridge/London, Harvard University Press.

HASENCLEVER, Andreas; MAYER, Peter; RITTBERGER, Volker. (1997), Theories of International Regimes. Cambridge, Cambridge University Press.

HELLER-ROAZEN, Daniel. (2009), The Enemy of All: Piracy and the Law of Nations. New York, Zone Books.

DADOS - Revista de Ciências Sociais, Rio de Janeiro, vol. 61, nº 1, 2018 


\section{Monica Herz e Roberto Vilchez Yamato}

HOLSTI, Kalevi J. (2004), Taming the Sovereigns: Institutional Change in International Politics. Cambridge, Cambridge University Press.

HURRELL, Andrew. (2005), "Power, Institutions, and the Production of Inequality", in M. Barnett; R. Duvall (eds.), Power in Global Governance. Cambridge, Cambridge University Press, pp. 33-58.

. (2007), On Global Order: Power, Values, and the Constitution of International Society. Oxford, Oxford University Press.

INAYATULLAH, Naeem; BLANEY, David L. (2004), International Relations and the Problem of Difference. New York/London, Routledge.

ICRC (International Committee of the Red Cross). (2003), International Humanitarian Law and the Challenges of Contemporary Armed Conflicts. Disponível em: https://www.icrc.org/eng/assets/files/other/ihlcontemp_armedconflicts_final_ ang.pdf. Acesso em 28/5/2017.

. (2007), International Humanitarian Law and the Challenges of Contemporary Armed Conflicts. Disponível em https://www.icrc.org/eng/assets/files/other/ihl-challenges-30th-international-conference-eng.pdf. Acesso em 28/5/2017.

(2011), International Humanitarian Law and the Challenges of Contemporary Armed Conflicts. Disponível em https://www.icrc.org/eng/assets/files/red-cross-crescent-movement/31st-international-conference/31-int-conference-ihl-challenges-report-11-5-1-2-en.pdf. Acesso em 28/5/2017.

. (2015), International Humanitarian Law and the Challenges of Contemporary Armed Conflicts. Disponível em https://www.icrc.org/en/document/international-humanitarian-law-and-challenges-contemporary-armed-conflicts. Acesso em $28 / 5 / 2017$.

JABRI, Vivienne. (2007), War and the Transformation of Global Politics. New York, Palgrave Macmillan.

KALDOR, Mary. (2007), New and Old Wars: Organized Violence in a Global Era. Cambridge, Polity.

KALSHOVEN, Frits; ZEGVELD, Liesbeth. (2001), Constraints on the Waging of War: An Introduction to International Humanitarian Law. Geneva, International Committee of the Red Cross.

KEENE, Edward. (2002), Beyond the Anarchical Society: Grotius, Colonialism and Order in World Politics. Cambridge, Cambridge University Press.

KENNEDY, David. (2006), Of War and Law. Princeton, Princeton University Press.

KEOHANE, Robert O. (1988), "International Institutions: Two Approaches". International Studies Quarterly, vol. 32, № 4, pp. 379-396.

KRASNER, Stephen D. (1983a), “Structural Causes and Regime Consequences: Regimes as Intervening Variables", in S. D. Krasner (ed.), International Regimes. Ithaca, Cornell University Press, pp. 1-21.

KRASNER, Stephen D. (ed.). (1983b), International Regimes. Ithaca, Cornell University Press. 
As Transformações das Regras Internacionais sobre Violência na Ordem Mundial...

KRASNER, Stephen D. (1999), Sovereignty: Organized Hypocrisy. Princeton, Princeton University Press.

(2010), "The Durability of Organized Hypocrisy", in H. Kalmo; Q. Skinner (eds.), Sovereignty in Fragments: The Past, Present and Future of a Contested Concept. Cambridge, Cambridge University Press, pp. 96-113.

LAUTERPACHT, Sir Hersch. (1968), International Law and Human Rights. USA, Archon Books.

LIGA DAS NAÇÕES. (1924), Convenção da Liga das Nações. Disponível em http: / / avalon.law.yale.edu/20th_century/leagcov.asp. Acesso em 24/12/2015.

LINKLATER, Andrew; SUGANAMI, Hidemi. (2006), The English School of International Relations: A Contemporary Reassessment. Cambridge, Cambridge University Press.

MACEDO, Stephen (ed.). (2006), Universal Jurisdiction. Philadelphia, University of Pennsylvania Press.

MALESEVIC, Sinisa. (2010), The Sociology of War and Violence. Cambridge, Cambridge University Press.

MORGENTHAU, Hans J. (2006), Politics among Nations: The Struggle for Power and Peace. New York, McGraw-Hill.

MUTUA, Makau. (2001), “Savages, Victims, and Saviors: The Metaphor of Human Rights". Harvard International Law Journal, vol. 42, no 1, pp. 201-245.

OETTE, Lutz. (2010), "Peace and Justice, or Neither? The Repercussion of the al-Bashir Case for International Criminal Justice in Africa and Beyond". Journal of International Criminal Justice, vol. 8, no 2, pp. 345-364.

ONU (Organização das Nações Unidas). (1945), Carta das Nações Unidas. Disponível em http://avalon.law.yale.edu/20th_century/unchart.asp. Acesso em $24 / 12 / 2015$.

ONUF, Nicholas G. (1998), “Constructivism: A User's Manual”, in V. Kubálková; N. Onuf ; P. Kowert (eds.), International Relations in a Constructed World. New York, M.E. Sharpe, pp. 58-78.

. (2008), International Legal Theory: Essays and Engagements, 1966-2006. London/New York, Routledge.

. (2013a), World of Our Making. London/New York, Routledge.

. (2013b), Making Sense, Making Worlds: Constructivism in Social Theory and International Relations. London/New York, Routledge.

ORFORD, Anne. (2011), International Authority and the Responsibility to Protect. Cambridge, Cambridge University Press.

ÖSTERDAHL, Inger. (2010), “Dangerous Liaison? The Disappearing Dichotomy between Jus ad Bellum and in Bello". Nordic Journal of International Law, vol. 78, no 4, pp. 553-566.

PARIS, Roland. (1997), "Peacebuilding and the Limits of Liberal Internationalism". International Security, vol. 22, no 2, pp. 54-89.

DADOS - Revista de Ciências Sociais, Rio de Janeiro, vol. 61, nº 1, 2018 


\section{Monica Herz e Roberto Vilchez Yamato}

. (2001), "Echoes of the Mission Civilisatrice: Peacekeeping in the Post-cold War Era", in E. Newman; O. Richmond (ed.), The United Nations and Human Security. Gordonsville, Palgrave, pp. 100-118.

. (2002), "International Peacebuilding and the 'Mission Civilisatrice'”. Review of International Studies, vol. 28, pp. 637-656.

. (2007), "Post-conflict Peacebuilding", in T. Weiss; S. Daws (eds.), The Oxford Handbook on the United Nations. New York, Oxford University Press, pp. 404-426.

PNUD (Programa das Nações Unidas para o Desenvolvimento). (1994), Human Development Report. New York, Oxford University Press.

POLICANTE, Amedeo. (2015), The Pirate Myth: Genealogies of an Imperial Concept. New York, Routledge.

RATNER, Steven R.; ABRAMS, Jason S. (2001), Accountability for Human Rights Atrocities in International Law: Beyond the Nuremberg Legacy. Oxford, Oxford University Press.

REUS-SMIT, Christian. (1997), "The Constitutional Structure of International Society and the Nature of Fundamental Institutions". International Organization, vol. 51, no 4, pp. 555-589.

. (1999), The Moral Purpose of the State: Culture, Social Identity, and Institutional Rationality in International Relations. Princeton, Princeton University Press.

. (2001), "Human Rights and the Social Construction of Sovereignty". Review of International Studies, vol. 27, pp. 519-538.

(2004a), "The Politics of International Law", in C. Reus-Smit (ed.), The Politics of International Law. Cambridge, Cambridge University Press, pp. 14-44.

(2004b) "Society, Power, and Ethics", in C. Reus-Smit (ed.), The Politics of International Law. Cambridge, Cambridge University Press, pp. 272-290.

(2013), "Constructivism", in S. Burchill et al. (eds.), Theories of International Relations. Hampshire/New York, Palgrave Macmillan, pp. 217-240.

RICHMOND, Oliver. (2004), "The Globalization of Responses to Conflict and the Peace Building Consensus". Cooperation and Conflict, vol. 39, no 2, pp. 129-150.

. (2005), The Transformation of Peace, Rethinking Peace and Conflict Studies. Basingstoke/New York, Palgrave Macmillan.

RITTBERGER, Volker (ed.). (1993), Regime Theory and International Relations. Oxford, Clarendon Press.

ROGERS, A. P. V. (2004), Law on the Battlefield. Manchester, Manchester University Press.

ROTHSCHILD, Emma. (1995), "What is Security?". Daedalus, vol. 124, no 3, pp. 53- 82.

SANDS, Philippe (ed.). (2003), From Nuremberg to The Hague. Cambridge, Cambridge University Press.

SASSÒLI, Marco; BOUVIER, Antoine A. (1999), How Does Law Protect in War? Cases, Documents and Teaching Materials on Contemporary Practice in International Humanitarian Law. Geneva, International Committee of the Red Cross. 
As Transformações das Regras Internacionais sobre Violência na Ordem Mundial...

SCHABAS, William A.; BERNAZ, Nadia. (2013), "Introduction", in W. A. Schabas; N. Bernaz (eds.), Routledge Handbook of International Criminal Law. London/New York, Routledge, pp. 1-2.

SCHMITT, Carl. (2003), The Nomos of The Earth: in the International Law of the Jus Publicum Europaeum. New York, Telos Press, Ltd.

SCHMITT, Carl. (2008), The Leviathan in the State Theory of Thomas Hobbes: Meaning and Failure of a Political Symbol. Chicago/London, The University of Chicago Press.

SCHWARZENBERGER, Georg. (1950), "The Problem of an International Criminal Law". Current Legal Problems, vol. 3, no 1, pp. 263-296.

SIMPSON, Gerry. (2004), Great Powers and Outlaw States: Unequal Sovereigns in the International Legal Order. Cambridge, Cambridge University Press.

. (2007), Law, War and Crime. Cambridge, Polity.

SINCLAIR, Adriana. (2010), International Relations Theory and International Law: A Critical Approach. Cambridge, Cambridge University Press.

TEITEL, Ruti G. (2011), Humanity's Law. Oxford, Oxford University Press.

THAKUR, Ramesh. (2017), The United Nations, Peace and Security: From Collective Security to the Responsibility to Protect. Cambridge, Cambridge University Press.

TPI (Tribunal Penal Internacional). (2005), “Darfur, Sudan". Disponível em https://www.icc-cpi.int/darfur. Acesso em 28/5/2017.

ULMEN, Gary L. (2007), "Partisan Warfare, Terrorism and the Problem of a New Nomos of the Earth", in L. Odysseos; F. Petito (eds.), The International Political Thought of Carl Schmitt: Terror, Liberal War and the Crisis of Global Order. London/New York, Routledge, pp. 97-106.

VIVEIROS DE CASTRO, Eduardo. (2011), A Inconstância da Alma Selvagem: E Outros Ensaios de Antropologia. São Paulo, Cosac Naify.

WALKER, Rob B. J. (1993), Inside/outside: International Relations as Political Theory. Cambridge, Cambridge University Press.

. (2010), After the Globe, Before the World. London/New York, Routledge.

WALTZ, Kenneth N. (1979), Theory of International Politics. New York, McGraw-Hill.

(2001), Man, the State and War: A Theoretical Analysis. New York, Columbia University Press.

WALZER, Michael. (2011), “On Humanitarianism. Is Helping Others Charity, Duty or Both?". Foreign Affairs, vol. 90, no 4, pp. 69-80.

WEBER, Max. (1994) [1919], “The Profession and Vocation of Politics", in P. Lassman; R. Speirs (eds.), Weber: Political Writings. Cambridge, Cambridge University Press, pp. 309-369.

. (2004), The Vocation Lectures. Indianapolis, Hacket Publishings.

WELSH, Jennifer M. (2004), "Introduction”, in J. M. Welsh (ed.), Humanitarian Intervention and International Relations. Oxford, Oxford University Press, pp. 1-7.

DADOS - Revista de Ciências Sociais, Rio de Janeiro, vol. 61, nº 1, 2018 


\section{Monica Herz e Roberto Vilchez Yamato}

WENDT, Alexander. (1992), "Anarchy is What States Make of It: The Social Construction of Power Politics". International Organization, vol. 46, no 2, pp. 391-425.

. (1999), Social Theory of International Politics. Cambridge, Cambridge University Press.

WHEELER, Nicholas J. (2000), Saving Strangers: Humanitarian Intervention in International Society. Oxford, Oxford University Press.

WIGHT, Martin. (1966), “Why is there no International Theory?", in H. Butterfield; M. Wight (ed.), Diplomatic Investigations. London, George Allen \& Unwin Ltd., pp. 17-34.

WIND, Marlene. (2001), “Nicholas G. Onuf: The Rules of Anarchy”, in I. B. Neumann; O. Waever (ed.), The Future of International Relations: Masters in the Making? London and New York, Routledge, pp. 236-268.

WIPPMAN, David. (2004), “The International Criminal Court", in C. Reus-Smit (ed.), The Politics of International Law. Cambridge, Cambridge University Press, pp. 151-188.

YOO, John; DELABUNTY, Robert J. (2005), “Memorandum for William J. Haynes II", in K. J. Greenberg; J. L. Dratel (eds.), The Torture Papers: The Road to Abu Ghraib. Cambridge, Cambridge University Press, pp. 38-79.

ZANOTTI, Laura. (2005), “Governmentalizing the Post-Cold War International Regime: The UN Debate on Democratization and Good Governance". Alternatives: Global, Local, Political, vol. 30, no 4, pp. 461-487.

ZEHFUSS, Maja. (2001), “Constructivisms in International Relations: Wendt, Onuf, and Kratochwil", in K. M. Fierke; K. E. Jorgensen (ed.), Constructing International Relations: The Next Generation. New York/London, M. E. Sharpe, pp. 54-75.

ZEHFUSS, Maja. (2002), Constructivism in International Relations. Cambridge, Cambridge University Press.

ZOLO, Danilo. (2009), Victors' Justice: From Nuremberg to Baghdad. London/New York, Verso. 
As Transformações das Regras Internacionais sobre Violência na Ordem Mundial...

RESUMO

As Transformações das Regras Internacionais sobre Violência na Ordem Mundial Contemporânea

Este artigo examina as transformações das regras internacionais sobre violência a partir de uma perspectiva construtivista de Relações Internacionais. Em particular, analisam-se as mudanças nas práticas sociais internacionais que têm ocorrido desde o fim do último século, discutindo-as em termos de regras internacionais que concomitantemente limitam e constituem as condições de possibilidade para o uso da violência. Na primeira parte, são mapeados e brevemente examinados cinco conjuntos de regras internacionais sobre violência: o direito internacional humanitário, o humanitarismo, o direito internacional dos direitos humanos, o direito internacional criminal e o regime de segurança coletiva. Na segunda parte, analisam-se as transformações político-normativa-sociais e conceituais que vêm ocorrendo na ordem mundial desde a década de 1990, dando particular ênfase à redefinição do conceito de segurança, à ressignificação do conceito de soberania e ao processo de expansão e confluência daqueles cinco conjuntos de regras internacionais. Argumenta-se que tais transformações das regras internacionais sobre violência, de um lado, expressam o deslocamento do dualismo doméstico/internacional e, de outro lado, ratificam o novo lugar do indivíduo nas relações internacionais. Com isso, sugere-se que é possível identificar mudanças significativas na arquitetura constitucional da ordem mundial contemporânea.

Palavras-chave: regras internacionais; violência; segurança internacional; soberania; ordem mundial

\section{ABSTRACT \\ Transformations to International Regulations on Violence in the Contemporary World Order}

The following article examines transformations to international regulations on violence based on a constructivist perspective of International Relations. A particular focus is awarded to shifts in international social practices to have occurred since the end of the last century, as discussing the terms of international regulations that both restrict and reinforce conditions in which violence may be used. The first section briefly maps and examines five sets of international regulations on violence: international humanitarian law, humanitarianism, international human rights law, international criminal law, and the collective security regime. In the second section, we analyze

DADOS - Revista de Ciências Sociais, Rio de Janeiro, vol. 61, no 1, 2018 
political-normative-social and conceptual transformations to have occurred to the world order since the 1990s, with a particular emphasis placed on the redefining of the concept of security, the new meaning given to the concept of sovereignty, and the process of expansion and convergence of these five sets of international regulations. We argue that such transformations to international laws on violence are both representative of the dislocation of domestic/international dualism and the new place of the individual in international relations. We therefore suggest that significant shifts may be identified in the constitutional architecture of the contemporary world order.

Key words: international regulations; violence; international security; sovereignty; world order

RÉSUMÉ

Les Transformations des Règles Internationales sur la Violence dans l'Ordre Mondial Contemporain

Cet article examine les transformations des règles internationales relatives à la violence à partir d'une perspective constructiviste des relations internationales. Nous analyserons en particulier les changements dans les pratiques sociales internationales survenus depuis la fin du siècle dernier et en débattrons en termes de règles internationales limitant et constituant concomitamment les conditions de possibilité de l'usage de la violence. Dans la première partie, on cartographiera et examinera brièvement cinq ensembles de règles internationales sur la violence: le droit international humanitaire, l'humanitarisme, le droit international basé sur les Droits de l'homme, le droit pénal international et le régime de sécurité collective. Dans la seconde partie, on analysera les transformations politiques, normatives, sociales et conceptuelles en cours au sein de l'ordre mondial depuis les années 1990 et l'accent sera mis sur la redéfinition des concepts de sécurité et de souveraineté, ainsi que sur le processus d'expansion et de confluence de ces cinq ensembles de règles internationales. D'un côté, ces modifications des règles internationales sur la violence expriment une transformation du dualisme domestique/international, et de l'autre, ratifient la nouvelle place de l'individu ans les relations internationales. On suggère ainsi qu'il est possible d'identifier des changements significatifs dans l'architecture constitutionnelle de l'ordre mondial contemporain.

Mots-clés: règles internationales; violence; sécurité internationale; souveraineté; ordre mondial 
As Transformações das Regras Internacionais sobre Violência na Ordem Mundial...

RESUMEN

Las Transformaciones de las Normas Internacionales sobre Violencia en el Orden Mundial Contemporáneo

Este artículo examina las transformaciones de las normas internacionales sobre violencia a partir de una perspectiva constructivista de las relaciones internacionales. En particular, se analizan los cambios en las prácticas sociales internacionales que se han producido desde finales del siglo XX, y se discuten en el marco de las normas internacionales que limitan y constituyen concomitantemente las condiciones para que prolifere el uso de la violencia. En la primera parte, se seleccionan y examinan brevemente cinco conjuntos de normas internacionales sobre violencia: el derecho humanitario internacional, el humanitarismo, el derecho internacional de los derechos humanos, el derecho penal internacional y el régimen de seguridad colectiva. En la segunda parte, se analizan las transformaciones sociales y conceptuales político-normativas que se vienen produciendo en el orden mundial desde la década de 1990, dando particular énfasis a la redefinición del concepto de seguridad, a la redefinición de concepto de soberanía y al proceso de expansión y confluencia de esos cinco conjuntos de normas internacionales. Se argumenta que tales transformaciones de las normas internacionales sobre violencia, por una parte, expresan el desplazamiento del dualismo doméstico/internacional y, por otra, ratifican el nuevo lugar que ocupa el individuo en las relaciones internacionales. Con ello, se sugiere que es posible identificar cambios significativos en la arquitectura constitucional del orden mundial contemporáneo.

Palabras clave: normas internacionales; violência; seguridad internacional; soberania; orden mundial

DADOS - Revista de Ciências Sociais, Rio de Janeiro, vol. 61, no 1, 2018 